Federal Reserve Bank of Dallas

Globalization and Monetary Policy Institute

Working Paper No. 240

http://www.dallasfed.org/assets/documents/institute/wpapers/2015/0240.pdf

\title{
Monetary Policy Expectations and Economic Fluctuations at the Zero Lower Bound ${ }^{*}$
}

\author{
Rachel Doehr \\ Claremont McKenna College \\ Enrique Martínez-García \\ Federal Reserve Bank of Dallas
}

May 2015

\begin{abstract}
Using a panel of survey-based measures of future interest rates from the Survey of Professional Forecasters, we study the dynamic relationship between shocks to monetary policy expectations and fluctuations in economic activity and inflation. We propose a smallscale structured recursive vector autoregression (VAR) model to identify the macroeconomic effects of changes in expectations about monetary policy. Our results show that when interest rates are away from the zero-lower bound, a perception of higher future interest rates leads to a significant rise in current measures of inflation and a rise in economic activity. However, when interest rates approach zero, the effect on economic activity is the opposite, with significant but lagged decreases in economic activity following an upward revision to expected future interest rates. The impact of changes in expectations about monetary policy is robust when we control for other features of the transmission mechanism (e.g., long-term interest rates, quantitative easing, exchange rate movements and even oil price shocks). Our findings also show that monetary policy expectations contribute up to 34 percent to the variability of economic activity (and 24 percent on inflation) while policy rates are fixed at the zero-lower bound. This evidence points to the importance of managing monetary policy expectations (forward guidance) as a crucial policy tool for stimulating economic activity at the zero-lower bound.
\end{abstract}

JEL codes: E30, E32, E43, E52

\footnotetext{
* Rachel Doehr, Claremont McKenna College, 742 Amherst Avenue, \#366, Claremont, CA 91711. 858444-7233, rdoehr16@cmc.edu. Enrique Martínez-García, Research Department, Federal Reserve Bank of Dallas, 2200 N. Pearl Street, Dallas, TX 75201. 214-922-5262. enrique.martinez-garcia@dal.frb.org. We thank Nathan Balke, Andrea Civelli, Víctor Valcárcel and Mark Wynne for helpful suggestions. We gratefully acknowledge the research assistance provided by Bradley Graves and Valerie Grossman, and the support of the Federal Reserve Bank of Dallas. We base our econometric analysis on the STATA program pvar.ado of Love and Ziccino (2006). All remaining errors are ours alone. The views in this paper are those of the authors and do not necessarily reflect the views of the Federal Reserve Bank of Dallas or the Federal Reserve System.
} 


\section{Introduction}

A growing strand of the literature on expectations-driven business cycles has tried to empirically answer the question of how changes in expectations of future macroeconomic variables drive the current macro aggregates. Leduc and Sill (2013) use survey-based forecasts of economic activity for the U.S. up to 2008 (extended to 2010) to show that changes in expectations of future economic activity are a significant driver of real economic activity and inflation. Leduc and Sill (2013) find that "a perception that good times are ahead typically leads to a significant rise in current measures of economic activity and inflation" and a monetary policy tightening. Leduc and Sill (2013) interpret this as evidence that changes in expectations about economic activity and their interaction with monetary policy are a significant driver of business cycles.

The work of Leduc and Sill (2013) supports the idea of an expectations-driven business cycle, and quantifies the impact of changes in expectations about the state of the world. This paper expands on the current literature by examining the effect of interest rate expectations on the macroeconomy and on the transmission mechanism of monetary policy. In that regard, we tackle two separate issues that do not explicitly arise in the preceding literature on the role of expectations in the business cycle.

First, we examine changes in the perception of monetary policy itself. Leduc and Sill (2013) consider changes in expectations about economic activity, but do not account for changes in perceptions about monetary policy that may otherwise be unrelated. Our approach instead is in line with the recent theoretical literature on the role of the expectations channel for monetary policy as policy rates become unresponsive. Eggertsson and Woodford (2003) 
argue that the future path of short-term interest rates affects long-term interest rates and, therefore, influences agents' optimal decisions as well as their perceptions about the economy. Carlstrom et al. (2012) and Del Negro et al. (2013), among others, have also found large macroeconomic effects on output and inflation from the management of expectations of future interest rates (forward guidance) when interest rates themselves become unresponsive for a period of time. Their findings suggest that long-term interest rates drive these macroeconomic effects, so we consider this dimension explicitly in modeling the transmission channel of monetary policy.

Second, we account for the fact that interest rates were fixed at the zero-lower bound during most of the period following the 2008 financial recession. The theoretical literature suggests that changes in perceptions about future interest rates can have significant effects when policy rates are fixed, providing rationale for policies that provide forward guidance as policy rates are bound at zero. The work of Leduc and Sill (2013) does not consider the possibility of a break in the effect that changes in perceptions about the future have on current economic activity and inflation, given that their sample contains only a few observations with interest rates near zero. We therefore extend the existing literature by examining the shifting role of monetary policy expectations, in particular by considering the effect the zero-lower bound has on the transmission of monetary policy and shocks to expectations on future monetary policy.

For those reasons, we focus our attention on the implications of changes in perceptions about monetary policy over the business cycle, especially in the wake of the 2008 financial crisis 
and the decision by the Federal Reserve to turn to unconventional monetary policy. As

documented in Contessi and Li (2013a, 2013b), forward guidance has played a significant role in the conduct of monetary policy for the U.S. as well as in a number of other major advanced economies during this period. In theory, by providing forward guidance about future policy rates, a central bank can affect interest rate expectations and long-term rates (as suggested in Eggerston and Woodford (2003), Carlstom et al. (2012) and Del Negro et al. (2012)). Filardo and Hofmann (2014) show that historically, forward guidance has had a significant effect on interest rate expectations.

This has become an issue of particular importance for policymakers not only due to the 2008 financial crisis, but also in the context of the historical downward trend in interest rates experienced over the past 40 years (see, e.g., Hamilton et al. (2015)). In an environment with low interest rates, episodes when policy rates hit the zero-lower bound or simply become fixed at low levels for an extended period of time are likely to be more frequent. ${ }^{2}$ We aim to provide a quantification of the shift that occurs on the macroeconomic response to shocks to expected future monetary policy as interest rates approach the zero-lower bound that can guide policymakers when considering the tradeoffs of implementing forward guidance.

In this paper, we empirically examine how interest rate expectations influence the transmission mechanism of monetary policy and affect current and future real economic

\footnotetext{
${ }^{2}$ The decline in the natural rate together with the success of monetary policy in attaining low inflation rates after the high inflation of the 1970s contributed to move nominal rates toward the zero lower bound even before the 2008 financial crisis. The concern - raised by Summers (2014) amongst others - is that this prolonged decline of low interest rates is a sign of 'secular stagnation' with the prospect of a future of lower per capita income growth and continued low interest rates. An alternative view is that the past weak growth and low interest rates may reflect the effects of a debt supercycle (see, e.g., Lo and Rogoff (2015)). After deleveraging and borrowing headwinds subside, expected growth rates may rise again and lead to higher interest rates in the medium term.
} 
activity and inflation. We use panel data of expectations about interest rates across forecasters in the Survey of Professional Forecasters and a structured recursive VAR for our analysis. By segmenting the panel dataset into the pre-2008 and post-2008 periods, we are able to differentiate between the effects of policy expectations shocks when policy rates are above zero compared to when they are at the zero-lower bound. We find that monetary policy expectations explain substantially more of the fluctuation in unemployment and inflation than the actual policy rate itself does. Most notably, during the post-2008 period at the zero-lower bound, expectations shocks account for 8 percent and 18 percent of the fluctuations in unemployment and inflation (1 year ahead) respectively, and close to 34 percent and 24 percent of the variability ( 5 years ahead). These findings suggest that the contribution of expectations shocks to fluctuations in real economic activity becomes stronger at longer horizons. We also provide evidence of a significant structural shift in the dynamic responses of real economic activity (and inflation) to expectations shocks when interest rates are at the zerolower bound.

Away from the zero lower bound, a positive innovation to future expected interest rates causes a decrease in the unemployment rate and a modest increase in inflation. However, at the zero-lower bound, a positive innovation to policy expectations leads to a lagged but substantial increase in unemployment, and a decrease in inflation after initially overshooting. When rates are bounded by zero, interest rate expectations provide some monetary accommodation by influencing the long-term rates even though the actual policy rate has been rendered ineffective. These results point to the importance of managing monetary policy expectations (forward guidance) for conducting an effective monetary policy, and provide 
further illumination into the actual transmission mechanism of monetary policy itself, in particularly at the zero-lower bound.

The rest of the paper is organized as follows: Section 2 discusses the role of the expectations channel for monetary policy, Section 3 presents a description of the data, Section 4 provides our empirical methodology, Section 5 presents the empirical results and our economic interpretation, and Section 6 summarizes our final conclusions.

\section{An Overview of the Expectations Channel of Monetary Policy}

The term structure of interest rates is the primary crucial part of the transmission channel of monetary policy. Under the assumption that monetary policy actions can be summarized with the short-term policy rate, policy transmission to the real economy and its effects on aggregate demand depend not only on current policy rates but also on the perceptions about monetary policy going forward that factor into longer-term interest rates (a point also stressed by Filardo and Hoffman (2014)). For zero-coupon bonds, an expectationbased interpretation of long-term interest rates contains an average of expected short-term rates over the maturity of the bond and a term and risk premium component. The log yield to maturity on an $n$-period nominal bond, $i_{n, t}$, may be represented as

$$
i_{n, t}=\frac{1}{n} \sum_{z=0}^{n-1} E_{t}\left(i_{1, t+z}\right)+\theta_{n, t}
$$

where $E_{t}$ denotes expectations at time $t ; i_{1, t+j}$ is the short (one-period) nominal rate in the $j$-th period of the forecasting horizon; and $\Theta_{n, t}$ is the term and risk premia required by investors to 
compensate them for holding longer-term bonds instead of rolling-over short-term debt.

Although the short-term interest rate can be viewed as a useful summary of the current stance of monetary policy responses, it is not the most accurate indicator of the transmission effects of monetary policy on aggregate demand, as suggested by Bernanke and Blinder (1992) among others.

It is, however, non-trivial to discern from long-term interest rates whether shocks to those long-term yields are due to unanticipated changes in policy rate expectations, or the latter term. This term $\Theta_{n, t}$ depends on illiquidity, default and duration risk. Duration risk refers to the asset price fluctuations investors are exposed to due to changes in inflation and interest rates over the maturity of the bond. Risk averse investors demand a premium for this risk, but the zero-lower bound may have ambiguous effects on interest rate volatility and the subsequent amount of risk that is priced into longer term yields. To illustrate the connection with the zero lower bound, let us assume that the distribution of policy rates is well approximated with a truncated Gaussian distribution. The zero bound induces a "positive" and increasingly significant bias in expected nominal rates as the mode of the interest rate distribution slides toward zero. This essentially means that the closer the policy rate is to zero the more it becomes a one-way bet with rates staying the same or going up-but not down-in the future. This positive bias prevents the volatility of the policy rate from falling as the mode of the distribution approaches zero. The indirect effect of a positive bias in expected rates on policy rate volatility, like the effect of increased uncertainty regarding the future monetary policy path, is consistent with the existence of a significant (and even rising) premia on long- 
term rates as policy rates approach zero. The effect of a binding lower bound on the policy rate in some models may even lead to increases in the volatility of real activity and inflation. ${ }^{3}$

Consequently, relying on long-term interest rates to model the term structure of interest rates and the transmission mechanism of monetary policy may confound the evidence, as long-term yields cannot disentangle the effect of changes in the expectation of future policy from uncertainty about the future path of policy. To get around this concern and explore the effectiveness of the transmission mechanism of monetary policy we use survey-based expectations of the future policy rate to isolate the expectation policy term and explore how unexpected innovations to expectations on monetary policy drive macroeconomic performance (and how the transmission of those innovations compares with that of innovations to the policy rate, especially at the zero lower-bound).

Examining the role innovations to policy expectations has on macroeconomic conditions further illuminates the transmission mechanism of monetary policy. The standard New Keynesian theory argues that, due to nominal rigidities, a policy-induced increase in the Federal Funds rate translates into changes in the real rate of interest above its natural rate, ${ }^{4}$ which entices economic agents to anticipate or postpone consumption, as well as influences investment decisions. When conventional monetary policy can no longer be enacted to provide

\footnotetext{
${ }^{3}$ Filardo and Hofmann (2014, pp. 42-44) more generally discuss three ways in which managing policy expectations can affect the economy: by affecting the perceptions of future expected interest rates, by lowering market volatility on interest rate expectations, and by making markets less sensitive to other news shocks. While we focus on the perceptions about future monetary policy, the other effects noted by these authors are relevant to our discussion as well. We must recognize that whether actively managed by policymakers through forward guidance or not, we must disentangle the effects of interest rate expectations from those of uncertainty about monetary policy itself, which manifests itself in changes to the risk premium on longer term yields, especially at the zerolower bound.

${ }^{4}$ The natural or Wicksellian rate is simply defined as the real interest rate that would prevail absent all nominal rigidities preventing the costless and instantaneous adjustment of prices in the economy.
} 
monetary accommodation due to the zero-lower bound, the aforementioned expectations theory of the term structure of interest rates suggests that expectations about future policy become a major channel for the transmission of monetary policy. If a central bank can effectively manage the private expectations about the future policy path, then a credible promise of lower short-term interest rates will be incorporated into lower long term interest rates today. Depressed long term interest rates then incentivize households to save less and consume more, while firms' opportunity cost of investing is lower, causing them to increase investment spending today.

As such, managing policy expectations (forward guidance) is a critical tool for monetary policymakers, especially given the current conditions in the U.S. Theory suggests that unless monetary policy alters perceptions regarding the future course of interest rates, then it will have no effect. While this would reduce nominal long-term interest rates, only if real interest rates are affected will consumption and investment respond (Lucas and Prescott (1971)). At the zero lower bound in particular, managing policy expectations through forward guidance can provide additional monetary stimulus. By examining market reactions to calendar-based forward guidance using futures rates and long-term interest rates from 2008 through 2013 in the U.S., the U.K. and the Euro-zone, Filardo and Hofman (2014) show that forward guidance caused a fall in futures rates (future interest rate expectations). The usefulness of this tool depends on the public's belief that the central bank will follow through with its commitment, and on the policy guidance being clearly and credibly communicated in a way that leads to the

\footnotetext{
${ }^{5} i_{t}=E_{t}\left(\pi_{t+1}\right)+r_{t}$ where $i_{t}$ is the nominal interest rate, $E_{t}\left(\pi_{t+1}\right)$ is the expected inflation rate next period and $r_{t}$ is the real interest rate.
} 
correct interpretation by households and firms (Filardo and Hofmann (2014), pp. 38-40).

Similarly, a fall in the liquidity and default premium represents another channel for monetary policy to have an effect on the macroeconomy -the Federal Reserve publicly acting like a 'buyer of last resort' leads to an increase in liquidity in the market through private investors becoming confident that the market would receive strong, ongoing central bank support (Joyce et al. (2011)).

In conjunction with the other channels, private agents' expectations regarding the future may be altered by forward guidance. For example, forward looking households could come to expect that a commitment to keeping interest rates low for an extended period of time will lead to an improvement in employment and wage outcomes. In turn, this would lead to higher spending and a boost in economic activity in the near-term. The plausibility and quantitative impact of this channel can be seen in the evidence provided by this paper, particularly in regards to the efficacy of expansionary monetary policy expectations shocks on economic activity at the zero-lower bound.

Addressing the challenges of the current economic environment requires thinking carefully about the trade-offs of unconventional monetary policy, and the potential use of interest rate expectations (forward guidance) as a policy tool in and of itself. Our paper contributes to this debate by providing a quantification of the size and dynamic effects on economic activity and inflation of expectations shocks to future policy based on the experience of the U.S. actively pursuing forward guidance while at the zero lower bound (see, e.g., Contessi and Li $(2013 a, b))$. 


\section{Empirical Analysis: Data}

We use interest rate forecasts from the Federal Reserve Bank of Philadelphia's Survey of Professional Forecasters (SPF). The SPF surveys a sample of between forty and fifty professional forecasters regarding real macroeconomic variables such as the inflation rate and real output growth. The SPF is a quarterly survey that dates back to 1968; however, the variable used in our analysis (forecasts of the three month Treasury bill rate) was included in the survey beginning in 1981. ${ }^{6}$ SPF provides a panel of one quarter, two quarter, three quarter, four quarter, current fiscal year, and next fiscal year forecasts. We use the longest consistent forecast horizon available (four quarters) in the VAR, together with the inflation rate based on the $\mathrm{CPI}$, the unemployment rate, and the Federal Funds rate. Figure 1 plots the expected four-quarter ahead forecast on the three month Treasury bill and the realized Federal Funds rate, shifting the expectations series four quarters back to account for the time difference arising from the forecast horizon. Figures 2 and 3 show density histograms of the policy expectations series after segmenting it into the 1981:Q3-2008:Q1 (non zero-lower bound) and 2008:Q2-2014:Q3 (zerolower bound) sub-samples.

The other variables used in our analysis - the inflation rate calculated from changes in the seasonally adjusted CPI level for all urban consumers, the seasonally adjusted civilian unemployment rate, ${ }^{7}$ the seasonally-adjusted annualized real GDP growth rate, the Federal Funds rate, total non-borrowed reserves of depository institutions, and the size of the

\footnotetext{
${ }^{6}$ The interest rate is not subject to revisions. By using forecasts of the interest rate, we do not face the difficulty of dealing with real-time forecasts on data that is subsequently subject to major revisions.

${ }^{7}$ The unemployment rate is also not subject to revisions. We therefore do not have the issue of real-time data that is subject to substantial revisions.
} 
monetary base-were all taken from the St. Louis Federal Reserve database. The data on the spot crude oil price (West Texas Intermediate) was taken from the Wall St. Journal / Haver Analytics, and the nominal trade-weighted value of the dollar series is from the Federal Reserve Board (Foreign Exchange Rates, G.5). ${ }^{8}$ The Shadow Federal Funds Rate is from the Federal Reserve Bank of Atlanta Center for Quantitative Economic Research, and was constructed by Cynthia Wu and Fan Dora Xia (Wu and Xia (2014)) to back out an indicator of monetary accommodation through unconventional monetary policy tools in terms of a Fed Funds rate "unconstrained" by the zero lower bound. All data is taken at quarterly intervals from 1981:Q3 through 2014:Q3.

We also use forecasts from the Livingston Survey of the Federal Reserve Bank of Philadelphia in a robustness check as our policy expectations variable, in which forecasters provide six months ahead, twelve months ahead, current fiscal year, and next fiscal year forecasts of the rate on the three month Treasury bill. To maintain consistency with our benchmark model and make use of the longest possible forecast horizon, we use the twelve month ahead forecast for the robustness check. This panel of forecasts is taken at semiannual intervals from 1992:S1 through 2014:S2, and gives us a significantly shorter sample size.

\footnotetext{
${ }^{8}$ The size of the monetary base, crude oil price, and nominal exchange rate were all transformed into quarterover-quarter percentage changes. We adopt growth rates here to maintain stationarity; however, including these variables in levels in the augmented models also yielded robust results that were in line with our other key findings on the propagation of expectations shocks
} 


\section{Empirical Analysis: Methodology}

Our approach uses a panel data Vector Autoregression (VAR) methodology. As in a traditional VAR approach, this methodology treats all the variables in the system as endogenous; however, the panel-data approach also allows for unobserved individual heterogeneity which arises in our context across individual forecasters. A useful discussion of panel VARs and their corresponding impulse-response functions can be found in Love and Ziccino (2006).

Our panel vector autoregressive (VAR) process incorporates $q$ variables as follows,

$$
\begin{aligned}
& z_{j t}=\Gamma_{0, t}+\Gamma_{1, t} z_{j t-1}+\ldots+\Gamma_{p, t} z_{j t-p}+f_{j}+Q_{t} \varepsilon_{t}, \\
& \varepsilon_{t}-N\left(0, I_{n_{t}^{z}}\right),
\end{aligned}
$$

where $z_{j t}$ is the $n_{t}{ }_{t} \times 1$ vector of endogenous variables at time tor forecaster $j, p$ is the number of lags in the specification, and $\varepsilon_{t}$ is consistent $n_{t}^{2} \times 1$ vector of exogenous shocks. We allow the dimension of $\mathrm{z}_{\mathrm{jt}}$ to potentially change over time so long as $\mathrm{n}_{\mathrm{t}}^{\mathrm{z}} \leq q . \Gamma_{0, t}, \ldots, \Gamma_{\mathrm{p}, \mathrm{t}}$ and $\mathrm{Q}_{\mathrm{t}}$ are the conformable matrices containing the unknown VAR parameters to be estimated. The likelihood of the model is invariant to orthonormal transformations of $\mathrm{Q}_{t}$ (that is, the contemporaneous impact of shocks on observed variables). We parameterize the likelihood function in terms of $\Sigma_{t}$ $=Q_{t}{ }^{\prime} Q_{t}$ and estimate this reduced form model. Only in a second step, we identify $Q_{t}$ based on a Cholesky decomposition.

We assume that the parameters only change when the interest rate hits or leaves the zero-lower bound (ZLB). Thus, we define for the lags $I=1, \ldots, p$ the following coefficients $\Gamma_{l, 1}=$ 
$\Gamma_{1, t \varepsilon\{Z \mathrm{ZLB} \text { not binding\}, }} \Gamma_{1,2}=\Gamma_{1, \mathrm{t}\{\{\mathrm{ZLB} \text { binding }\}}, \Sigma_{1,1}=\Sigma_{1, t \varepsilon\{Z \mathrm{LB} \text { not binding }\}}$, and $\Sigma_{1,2}=\Sigma_{1, t \varepsilon\{Z \mathrm{LB} \text { binding }\}}$ for our VAR specification in (2). This approach is conceptually related to a TVP-VAR (Time-Varying Parameter VAR) model with occasional jumps or a pure-regime switching approach. However, a more notable difference is that we assume the shift in the parameters only occurs as a function of the state of the economy-when the monetary policy is constrained by the zero-lower bound. In a TVP-VAR model, parameter innovations are instead treated as independent of the observed variables and subsequently are independent of the path of the policy rate. We think the underlying assumptions of the TVP-VAR model are, therefore, less desirable when studying parameter changes resulting from policy reaching the zero-lower bound constraint. We believe that our approach is more appropriate to capture the potential dynamic shifts that occur in the data, as economic theory suggests that the break point depends on the state of the economy and ought to occur whenever the constraint becomes binding.

In applying the panel VAR procedure to our data, we allow for "individual heterogeneity" in the levels of the variables by introducing fixed effects across forecasters, with the term $f_{j}$ in the specification in (2). Mean-differencing to eliminate the fixed effects creates biased coefficients because of correlated regressors in the model specification due to lags of the dependent variables. We follow the Helmert procedure proposed by Arellano and Bover (1995) of forward mean-differencing to effectively deal with this problem. ${ }^{9}$ The Helmert transformation preserves the orthogonality between transformed variables and lagged

\footnotetext{
${ }^{9}$ Forward-mean differencing removes the mean of all the future observations available for each forecaster-period pair.
} 
regressors, so it should not affect the estimates of the coefficients by system GMM, and allows us to use the lagged regressors as instruments in the VAR specification.

We focus our analysis on the impulse-response functions, which describe the response of one variable in the system to a positive one standard deviation innovation to another variable in the system (setting all other shocks to zero). Since the impulse-response functions are constructed from the estimated VAR coefficients, their standard errors need to be taken into account in order to construct the confidence intervals for the impulse-response functions. We report confidence intervals on the impulse-response functions generated by using 500 Monte Carlo simulations.

Since the variance-covariance matrix of the errors $Q_{t}$ is generally not diagonal, we need to decompose the residuals so that they become orthogonal. We therefore adopt a particular ordering and impose a Choleski decomposition that allocates any correlation between the residuals to the variable that comes first in the preset ordering. This approach is equivalent to a recursive VAR specification-the variables that come earlier in the ordering affect the following variables contemporaneously, as well as with up to $p$ lags. The variables that come later only affect the ones preceding them with some lag, but not contemporaneously.

Following Leduc and Sill (2013), we structure our VAR with a recursive identification scheme, placing the expected interest rate first, followed by the inflation rate, the unemployment rate, and finally the Federal Funds rate. ${ }^{10}$ This recursive ordering is specifically

\footnotetext{
${ }^{10}$ We also worked with a benchmark model using the real GDP growth rate instead of unemployment as our proxy for economic activity. The results when using real GDP growth were consistent with the VAR model structured with
} 
motivated by the timing of the survey data. Forecasters only have past information available to them-specifically last quarter's inflation, unemployment, and Federal Funds rate-when they form expectations. Thus, agents' forecasts are dependent solely on these historical values, which permits us to place the expectations variable above all others in the model. Inflation is placed next in the model, as it is responsive to current nominal interest rate expectations as well as historical economic activity and the Federal Funds rate. The policy tool, the Federal Funds rate, is placed last in the ordering, as it responds contemporaneously to fluctuations in current economic conditions.

Small-scale VARs like the one we consider may suffer from misspecification due to omitted variables, given that the specification may prove to be insufficient at capturing the complex factors that affect the macro aggregates. We consider also augmented VAR specifications that incorporate other important features of the economic environment and the monetary transmission mechanism not captured in our benchmark. ${ }^{11}$ However, including survey expectations in the benchmark VAR framework can mitigate this problem to some extent, given that professional forecasters and economic agents likely use a richer information set to make forecasts (a point also raised in Leduc and Sill (2013)). Our findings indicate that survey expectations about future interest rates contain important information about the path of monetary policy not directly incorporated in our small-scale VAR specification through other macro variables.

the unemployment rate and are available upon request. The unemployment rate data in our model has the advantage that it is less subject to data revisions and avoids this issue in our econometric analysis.

${ }^{11}$ We discuss the ordering of the variables for each one of those variants of the model later on explaining our robustness checks. 
One possible interpretation of the shocks to interest rate forecasts that we recover from the VAR is based on the growing literature on news shocks about future fundamentals (see, e.g., Beaudry and Portier (2006)). It is also connected to the recent literature on forward guidance that explores the idea of news shocks about future monetary policy (see, e.g., Del Negro et al. (2013)). To the extent that the VAR can account for all the factors that drive interest rate forecasts, an innovation to the expectations (forecasts) about future monetary policy would represent an autonomous change in expectations about future monetary policy, and can be interpreted as news about future monetary policy. The proposed VAR methodology, however, cannot identify news shocks. Our results - as those of Leduc and Sill (2013) - show that expectations contain additional information that is useful to account for the observed behavior of macroeconomic variables and their interaction with monetary policy. Our interpretation of the innovations to monetary policy forecasts is that they reflect upwards/downward revisions to expectations of future monetary policy. Hence, innovations to monetary policy expectations incorporate information about the future path of policy (news), but also changes in current fundamentals that are not already fully reflected in the model.

\section{Empirical Analysis: Findings}

To perform the VAR analysis specifically on panel data, we utilize the user-written Stata program pvar.ado, written and made available to the public by Inessa Love (see Love and Ziccino (2006)). ${ }^{12}$ Although we tried several different lag order selection lengths, the first lag

\footnotetext{
${ }^{12}$ The codes of Love and Ziccino (2006) that we use implement the panel VAR methodology of Holtz et al. (1988).
} 
continued to be the only significant regressor across all variables, so the benchmark and augmented models were run using a first order lag $(p=1)$ specification. ${ }^{13}$

The general model in (2) allows for breaks in the coefficients as the economy hits the zero-lower bound. In principle, this more general model allows for the possibility that the coefficients will be exactly the same in both periods, so we formally analyze this stability issue using a Chow test to let the data give an answer on whether the model dynamics truly change across these two periods. Given the known break point in the data-2008:Q2, when rates are expected to be constrained at zero within the next year ${ }^{14}$-we calculate the Chow test Fstatistic using residuals from a "pooled" model that includes the entire dataset and residuals from the split sample models. We limit the degrees of freedom used in the Chow test and pooled model to a reasonable number by theorizing that the key structural shift results primarily from changes in the transmission of monetary policy (the Federal Funds rate) and monetary policy expectations (the SPF forecasts) shocks. Applying these criteria, we find strong evidence for a structural shift at the zero-lower bound, with an F-statistic of 34.08 that rejects the null hypothesis of parameter stability at the $99 \%$ confidence level ( $p$-value of $<0.001)$. The

\footnotetext{
${ }^{13}$ The non-zero lower bound sample (1981:Q3-2008:Q1) minimized Hansen's J-statistic with a first order lag corresponding to a coefficient of determination of 0.999669 (J-statistic of $1.04 \mathrm{e}^{-28}$ ). The zero-lower bound sample (2008:Q2-2014:Q3) minimized Hansen's J-statistic with a first order lag corresponding to a coefficient of determination of 0.999457 ( $\mathrm{J}$-statistic of $1.26 \mathrm{e}^{-28}$ ). Further details on the lag selection results are available upon request from the authors.

${ }^{14}$ In fact, the Fed Funds rate still went down a bit after 2008:Q1 until it became stuck at the zero-lower bound. We split our sample after 2008:Q1 for two reasons: (a) policy rates were already near the zero-lower bound and quickly moving towards it; and (b) given the worsening economic conditions (at the beginning of the recession) and the expected monetary policy response based on the historical experience since the 1980s, policymakers, consumers and investors already were anticipating that degree of monetary accommodation required to deal with the crisis over the upcoming years could not be accommodated with conventional policies-that is, with further and deeper cuts of the Fed Funds rate-and may require unconventional policy tools (including forward guidance) instead. It is primarily due to the fact that almost since the onset of the recession private agents and policymarkers alike incorporated into their expectations the prospect that policy rates will become constrained at the zero-lower bound in the near future that we choose to split the sample around 2008:Q1 (four-quarters ahead of the actual point in time at which the Fed Funds rate effectively hit the zero-lower bound).
} 
results confirm the striking reversal we find in the following Impulse-Response functions to ultimately show that there has been a significant regime switch in the benchmark model at the zero-lower bound. With this evidence, we proceed with our estimation strategy that treats the two regimes-zero lower bound and non zero-lower bound-as separate.

Given the unique economic conditions of the zero-lower bound sample, we consider the Federal Funds rate and other price-based measures of the stance of monetary policy in specification. Prior to the Great Recession, the Federal Reserve's primary tool for achieving its objectives had been the short-term interest rate (Mishkin (2007)). However, this price-based framework for the conduct of monetary policy can-and has become-constrained at the zerolower bound. Blinder (2000) identifies a range of unconventional policies that the central bank can still deploy when policy rates are fixed at zero. Bernanke and Reinhart (2004) narrow these down to the two most plausible 'unconventional' tools: (a) policies which shape expectations of future interest rates (forward guidance), and (b) policies that expand the size (quantitative easing) or shift the composition of the central bank's balance sheet (credit easing). While the effective Federal Funds rate moves much during this period, our benchmark identification of monetary policy naturally incorporates the former type of 'unconventional' policies explicitly into the model by including both the short-term policy rate as well as expectations of future policy.

Apart from the effective Federal Funds rate, we investigate two alternative price-based measures of the stance of monetary policy ${ }^{15}$ First, we look at the Shadow Rate of Wu and Xia

\footnotetext{
${ }^{15}$ See Figures 7b, 7c, and 7d in Appendix for select key Impulse-Response Functions of the benchmark model augmented with different measures of price-based monetary policy.
} 
(2014) which uses financial data to translate the effects of the broad range of unconventional monetary policies pursued by the Federal Reserve into equivalent changes of a shadow Federal Funds rate "unconstrained" by the zero-lower bound. Then, we also work with the slope of the yield curve, measured as the spread between the long and short term interest rates, which indicates market expectations of increasing (decreasing) future policy rates under the expectations hypothesis of the term structure (as shown in equation (1)). However, the yield curve also incorporates a time-varying term and risk premium component that can make it difficult to disentangle the expected path of monetary policy. Nonetheless, both price-based measures confirm our key results on the importance of policy expectations, particularly at the zero-lower bound.

Given that all of these competing price-based measures of the stance of monetary policy at the zero-lower bound have their own disadvantages and that our results on the effects of policy expectations shocks remain robust across the various measures, we retain the Federal Funds rate in the specification of our benchmark model. We believe that in this wayour findings are less likely to be contaminated by other factors (risk premia, liquidity premia, etc.) associated with these alternative price-based measured. In addition, following on Bernanke and Reinhart (2004)'s classification of 'unconventional' policy tools, wealso incorporate quantitybased measures of the stance of monetary policy in later variants of the benchmark model augmented with monetary aggregates to explicitly account for the role of quantitative easing in setting the tone of the U.S. monetary policy after the Great Recession. ${ }^{16}$ Once again, we show

\footnotetext{
${ }^{16}$ The effects of adding quantity-based measures of monetary policy are discussed extensively in later sections; see Figures 11a, 11b, 11c and 11d, as well as Figures 12a, 12b and 12c.
} 
that our findings on the role of expectations about future monetary policy are robust to a modelling specification for monetary policy that distinguishes between price-based and quantity-measures.

\section{Benchmark Panel VAR Model: Results}

We split the data into non zero-lower bound (1981:Q3-2008:Q1) and zero-lower bound (2008:Q2-2014:Q3) periods and estimate the model over the two split samples using the recursive ordering discussed previously. The benchmark model and corresponding variance decomposition and Impulse-Response functions yield several significant insights. We find that interest rate expectations explain more of the fluctuations in unemployment and inflation than the actual Federal Funds rate does, at both the zero-lower bound as well as the non zero-lower bound (see Figure 6). The percentage of variation in the unemployment rate explained by interest rate expectations 1-year ahead is $7.61 \%$ at the zero-lower bound, down from $11.83 \%$ during the non-zero lower bound period. Similarly, the percentage of variation in the inflation rate explained by policy expectations at the zero-lower bound grows to $23.87 \%$ 1-year ahead from $2.79 \%$ during the non zero-lower bound period. The role of policy expectations is of particular importance in explaining long term fluctuations in economic activity. The share of the variability of unemployment explained 5-years ahead is quite larger than 1-year ahead-in fact, the amount of fluctuations 5-years ahead explained by policy expectations grows from $7.37 \%$ during "normal monetary policy" times to $34.2 \%$ at the zero-lower bound. The contribution to the variability of inflation 5 -years ahead at $24 \%$ remains significantly higher than the $3.56 \%$ away from the zero-lower bound, but similar to the share of variability explained 1-year ahead. 
The most striking results come from an analysis of the Impulse-Response functions (see Figure 7). When interest rates are not bound by zero, a positive one standard deviation shock to interest rate expectations leads to a decrease in the unemployment rate, while a similar shock to the Federal Funds rate causes the opposite-though lagged-reaction in economic activity: an increase in the unemployment rate of a larger magnitude but opposing direction. We theorize that the counterintuitive reaction of the unemployment rate to policy expectations shocks away from the zero-lower bound could be due to a signaling effect from the level of the interest rate. In other words, during "normal monetary policy" times, if there is a negative shock to future expected interest rates (a downward revision to the policy path), instead of seeing this as an incentive to engage in more spending today, economic agents are concerned that lower future interest rates are a result of the Fed engaging in unexpected future monetary accommodation, reflecting a worsening of the Fed's own views about future economic conditions. So rather than provide a stimulus boost to the economy today, firms and households postpone projects and consumer spending, fearful of future depressed demand and economic activity.

However, at the zero-lower bound, the signaling mechanism works quite differently. The zero-lower bound is only a constraint for monetary policy if economic conditions warrant a further accommodation today. Therefore, if there is an upward revision to future monetary policy while at the zero lower bound, it can only mean that economic conditions are improving more (or faster) than expected, which would then justify why future monetary policy is now expected to tighten. In that case, economic agents have an incentive to postpone investment and consumption decisions because short-term rates are unchanged but long-term rates are 
rising due to the term structure of interest rates. ${ }^{17}$ This means that expectations shocks at the zero-lower bound behave almost as shocks to the policy rate itself in "normal monetary policy" times. We even find the reaction of the unemployment rate to a policy expectations shock at the zero-lower bound is of a similar magnitude to the corresponding reaction from a shock to the Federal Funds rate during "normal monetary policy" times, although it is lagged, becoming significant in the data only after 2 quarters.

The fact that interest rates are constrained downwards at the zero-lower bound suggests that the transmission of other shocks also changes as their interaction with monetary policy through the policy rate becomes constrained. For example, away from the zero-lower bound, a positive unemployment rate shock leads to a lower Federal Funds rate today and an expectation of lower interest rates in the future. This helps to mitigate the impact on economic activity, but leads to temporarily lower inflation while unemployment remains elevated. At the zero-lower bound, a positive unemployment rate shock leads to a modest decline in the Federal Funds rate, but an expectation of higher future interest rates. This, in turn, results in a small positive increase in inflation. Given that the policy tool itself cannot go much lower on impact during this period of near-zero rates, the response of monetary policy expectations becomes even more relevant.

\footnotetext{
${ }^{17}$ We more closely examine the impact of expectations shocks on farther out on the yield curve in a later section, see Figures $12 a, 12 b$, and $12 c$.
} 


\section{Augmented Panel VAR Models: Results}

To thoroughly analyze the effect of monetary policy expectations shocks on the economy, we extend our benchmark model to control for several variables that could be influencing our results - the exchange rate channel of monetary policy (using the nominal exchange rate), effects of global economic developments (shocks to oil prices), the monetary policy transmission mechanism (long-term interest rates), unconventional monetary policy during the 2008 financial crisis (proxied by the size of the monetary base and the Shadow Federal Funds rate) - as well as utilize the Livingston Survey as a further robustness check.

\section{The Exchange Rate Channel of Monetary Policy}

The effect of monetary policy on economic activity with open capital markets through the exchange rate is well documented and represents another major channel for the transmission of monetary policy (Bernanke et al. (2004)). In the short-run and with prices slow to adjust, a nominal exchange rate depreciation equates to a real depreciation, and therefore a short-run improvement in net exports (Krugman (2000)). The nominal depreciation potentially induced by policy would therefore stimulate economic activity, at least in the short term.

To first identify the exchange rate channel in our augmented model, we include the nominal exchange rate, placing it immediately following the Federal Funds rate, so that changes to domestic future monetary policy expectations, current inflation, and the actual policy tool all drive fluctuations in the exchange rate. Figures $8 a$ and $8 b$ show the Impulse-Responses of the unemployment rate and nominal exchange rate to an innovation in the expected interest rate Comparing these to our benchmark model, we find that including the exchange rate does not 
change our conclusions on the underlying structural shift in the dynamic response to monetary policy expectations shocks that occur at the zero-lower bound.

Our results are consistent with Eichenbaum and Evans (1995) in that following a policy rate shock during "normal policy times," the exchange rate modestly appreciates and it does so over a prolonged period of time. ${ }^{18}$ At the zero-lower bound, however, the U.S. dollar depreciates in response to a contractionary policy shock (see Figure 8c). We interpret this as evidence that in "normal economic times," the exchange rate channel amplifies traditional monetary policy-a contractionary shock leads to an appreciation of the domestic currency, and a corresponding decrease in exports, further depressing economic activity. However, at the zero-lower bound, there is a reversal in the behavior of the exchange rate channel, as a contractionary monetary policy shock is dampened by a significant depreciation in the U.S. dollar. Meanwhile, shocks to monetary policy expectations have stronger effects on the exchange rate during "normal policy times," going in the same direction as shocks to the Federal Funds rate (see Figure $8 a$ and Figure $8 c$ ), although the dampening effect that this may have on the foreign sector does not prevent economic activity from rising at the same time (see Figure $8 b$ ). At the zero-lower bound, unemployment increases but the effects of positive shocks to monetary policy expectations on the U.S. dollar are largely muted (see Figure 8a), as they become statistically insignificant.

\footnotetext{
${ }^{18}$ Eichenbaum and Evans (1995) provide evidence of systematic deviations from the uncovered interest rate parity (UIP) condition. UIP in its simplest form suggests that the expected future change in the exchange rate equals the difference between domestic and foreign nominal interest rates.
} 
Global Economic Developments: Oil Shocks

We incorporate global developments that may have not been properly reflected in the benchmark model but may be important for the perceptions of economic agents and policy makers in the U.S. Oil is priced in global markets and therefore picks up these international developments, so we exogenize oil prices in the model. Oil is placed last in the ordering, so that it contemporaneously affects all other variables, but is only influenced by lagged values of the other policy, expectations and macro variables. We highlight two important findings - first, that even after adding in this proxy for global economic developments, expectations behave similarly to the previous findings in our benchmark model, both at the zero-lower bound as well as during "normal monetary policy" times (see Figure 9a). Second, by adding in oil prices to the model specification, we successfully mitigate the "price puzzle" that arises in the benchmark model. ${ }^{19}$ In other words, we see in Figure 7 that in the benchmark model, a positive monetary policy shock generates a significant uptick in inflation rather than a decline, as one would expect from most conventional monetary models. Adding in oil prices significantly dampens this effect in "normal economic times" and completely reverses it at the zero-lower bound (see Figure 9b), while preserving the main findings about monetary policy expectations obtained with the benchmark model.

\footnotetext{
${ }^{19}$ Sims (1992) was among the first to propose the introduction of commodity prices to resolve the price puzzle. Sims (1992) and Giordani (2004) argue that the price puzzle may simply arise because policy rate innovations partially reflect unmodelled inflationary pressures that lead to price increases and, in that sense, oil prices in the VAR appear to capture enough additional information about those inflationary pressures that it may resolve the price puzzle.
} 


\section{The Transmission Mechanism of Monetary Policy: Long-Term Interest Rates}

To further examine the role of interest rate expectations on economic activity, we also consider other important aspects of the transmission mechanism of monetary policy: long-term interest rates. We include the yield on the ten year U.S. Treasury bill in our benchmark model, placing it directly after the unemployment rate and immediately prior to the Federal Funds rate. This is motivated by the expectations channel of monetary policy discussed previously-a change to the Federal Funds rate not only affects investment and consumption decisions directly through changes to short-term rates, but by also lowering expectations of future short term rates and, therefore, long-term yields which incorporate these lower current and future short-term rates. Thus, long-term rates respond contemporaneously to shocks to the Federal Funds rate, while economic activity (the unemployment rate) is determined in part by lagged values of both the short-term and long-term interest rates. The results from our ImpulseResponse functions confirm this theory, with intriguing shifts happening at the zero-lower bound (see Figures 10a, 10b and 10c). A positive shock to short-term interest rate expectations leads to an increase in the yield on the ten year U.S. Treasury at both the non zero-lower bound as well as at the zero-lower bound. We also find that a shock to long-term rates alone is not enough to cause a statistically significant change in economic activity when the Federal Funds rate is at "normal" levels; however, when the policy tool becomes bound by zero, a shock to long-term rates has a substantial effect on today's unemployment rate. Echoing this is the reaction to innovations in short-term rate expectations by the unemployment rate-again, we find that at the zero-lower bound a positive shock to expectations drives a significant increase 
in unemployment, the reverse of the reaction in normal conditions when monetary policy is unconstrained.

These findings have interesting implications in regards to the behavior of the yield curve. In "normal economic times," as well as at the zero-lower bound, a positive shock to expectations of short term rates leads to an increase in the rate on the ten year U.S. Treasury (see Figures $10 a, 10 b$ and $10 c$ ). The same positive shock to expectations also increases today's short term rates (albeit much more modestly at the zero-lower bound). However, a downward revision of expected future short term rates can have a significantly different impact on the shape of the yield curve when the economy is at the zero-lower bound-long term rates would be adjusted somewhat downward, while short term rates remain fixed at zero, unable to respond much further to the negative innovation to expectations, moving the slope of the yield curve in a downwards direction and stimulating economic activity today. Away from the zerolower bound, innovations to expectations of future monetary policy are able to immediately be incorporated into both short term and long term rates, and therefore do not necessarily lower the slope of the yield curve itself, or does so by a lesser magnitude than it does when short term rates are bounded by zero.

This further illustrates the strength of the transmission mechanism of monetary policy expectations in an economy at the zero-lower bound: changes in expected future short term rates affect long term rates as well as significantly impact the slope of the yield curve, stimulating investment decisions and economic activity today. Declining yield curves tend to be associated with recessions in "normal policy" periods, as they are indicative of lowered 
expectations on the future prospects of the economy (thus, requiring more expansive monetary policies for supported than anticipated). At the zero-lower bound, this lowering in the slope of the yield curve signals that the central bank is willing to provided more monetary accommodation than was expected over time. Given that current policy rates are stuck at zero, the decline in long-term rates that follows from incorporating those revised expectations helps boost the economy today, as private households and firms anticipate their consumption and investment decisions in response to the declining long-term rates. Given the significant role that these innovations to policy expectations have on output (see Figure 10b), they may also play an important part in bringing the economy back on its path. Furthermore, our results suggest that at the zero-lower bound, the slope of the yield curve may be less accurate as an indicator of the likelihood of a recession than it had traditionally been before (see, e.g., Rudebusch and Williams (2009)).

\section{Quantitative Easing at the Zero-Lower Bound}

Given the extraordinary actions of the Federal Reserve in expanding the size of the monetary base during the 2008 financial crisis through asset purchase programs and other related initiatives aimed at expanding the Fed's balance sheet, we add the St. Louis Adjusted Monetary Base as an exogenous variable to control for this potential confound. Figures $11 a$ and $11 b$ show the Impulse-Response functions to an innovation in the expected interest rate in the augmented VAR model. We maintain the same recursive ordering as in the benchmark but add the monetary policy last, as an exogenous variable. Comparing these to the results from the benchmark model, we find no significant change in the reaction of economic activity to policy 
expectations shocks, nor to the significant reversal of behavior at the zero-lower bound. However, we find that the increase in the unemployment rate following a positive upward revision on the expectations of future monetary policy accrues faster, turning positive immediately after the shock (unlike in the benchmark model).

This augmented VAR also allows us to examine the efficacy of quantitative easingproxied by expansions of the monetary base-on economic activity at the zero-lower bound and how its macro effects compare to those of shocks to interest rate expectations. During "normal policy" times, a positive change to the growth of the monetary base has a statistically insignificant effect on inflation, but causes a substantial decrease in the unemployment rate (see Figures $11 \mathrm{c}$ and $11 d$ ). On the other hand, at the zero-lower bound, these same shocks to the growth of the monetary base lead to modest increases in both inflation and the unemployment rate. Although statistically significant, the effects of a shock to the growth rate of the monetary base are rather small. In particular, the impact of a shock to the growth rate of the monetary base on unemployment is approximately twice as large as that of a policy rate shock at the zero-lower bound. However, our findings also show that the effect of unemployment to shocks to expectations of future policy is a lot larger than the combined effects of both shocks to the policy rate and to the growth rate on the monetary base. The quantitative importance of these expectations shocks relative to other policy-related shocks is the key takeaway that we would like to highlight. We argue that these results also showcase the importance and efficacy of managing expectations about future policy (forward guidance) at the zero-lower bound. 
We also confirm our findings on the dynamic responses to expectation shocks by next substituting in the total non-borrowed reserves of depository institutions for the monetary base. It remains the case that a positive shock to interest rate expectations leads to a substantial increase in the unemployment rate at the zero-lower bound (see Figure 12a).

In this augmented model, a positive shock to non-borrowed reserves at the zero-lower bound causes a decrease in the unemployment rate that becomes insignificant after four quarters, while a positive shock to the Federal Funds rate is contractionary and yields an increase in the unemployment rate (see Figures $12 b$ and $12 c$ ). This provides evidence that at the zero-lower bound, if we account for the unprecedented quantity-based monetary policies undertaken by the Federal Reserve by way of non-borrowed reserves, the stimulating effects on economic activity of such unconventional policies appear small-smaller than shocks to expected future monetary policy at the zero-lower bound (see Figure 12a and 12c)-and shortlived compared to an expansionary (negative) shock to expected future monetary policy (see Figure 12a). This suggests that credible and well-communicated forward guidance can be amongst the most effective tools that the central bank can deploy when conventional policy becomes constrained at the zero-lower bound.

\section{Alternative Survey-Based Forecasts: The Livingston Survey}

We complete our robustness checks of the empirical model by utilizing a different measure of policy expectations, the Livingston Survey. While maintaining the same recursive ordering and split sample as in the benchmark model, we replace the SPF policy expectations term with the equivalent from the Livingston Survey and substitute the quarterly data for 
semester data using an averaging aggregation method. The results are shown in Figure 13, and are virtually the same as those found when using the SPF data. Consequently, we conclude that expectations of monetary policy are not only an important driver of current macroeconomic variables, but the behavior of economic agents undergoes a significant and quantitatively important change when interest rates hit the zero-lower bound.

\section{Concluding Remarks}

The intriguing shift in the dynamic responses to policy shocks and shocks to expectations about future monetary policy shows that the transmission mechanism of monetary policy changes when interest rates edge toward the zero lower bound. In this paper we empirically investigate the transmission mechanism of monetary policy and expectations with a small-scale VAR model that builds on the approach of Leduc and Sill (2013) to assess expectations-driven business cycles. We find that future short term interest rate expectations become a highly significant driver of variability in economic activity and inflation, as the policy expectations become incorporated into long-term interest rates. As the policy rates become stuck at the zero-lower bound, the behavior of the monetary transmission mechanism itself changes-shocks to expectations themselves, rather than the policy tool, are what influence economic activity (and inflation). In this regard, we find strong evidence that downward revisions to expected future monetary policy one-year ahead can have lagged but large effects on economic activity when policy rates approach zero. 
Hence, even at the zero lower bound, the central bank can still use forward guidance to provide additional stimulus. Although shocks to monetary policy expectations were shown to have limited effects during normal policy times, the importance and dynamic effects of these shocks changes significantly at the zero lower bound. In that regard, policy expectations and forward guidance become crucial tools for stimulating the economy. Managing policy expectations provides a significant opportunity for potentially guiding an economy when conventional monetary policy is no longer a realistic option. 


\section{Bibliography}

Arellano, Manuel and Olympia Bover (1995): “Another Look at the Instrumental Variable Estimation of Error Component Models." Journal of Econometrics, vol. 68 (1): 29-51.

Beaudry, Paul and Franck Portier (2006): "Stock Prices, News, and Economic Fluctuations." American Economic Review, vol. 96 (4): 1293-1307.

Bernanke, Ben S. and Alan S. Blinder (1992): "The Federal Funds Rate and the Channels of Monetary Transmission." American Economic Review, vol. 82 (4): 901-921.

Bernanke, Ben S., Reinhart, Vincent R. and Sack, Brian P. (2004): “Monetary Policy Alternatives at the Zero Bound: An Empirical Assessment." Brookings Papers on Economic Activity, vol. 2004 (2): 1-78.

Carlstrom, Charles T., Timothy S. Fuerst and Matthias Paustian (2012): "Inflation and Output in New Keynesian Models with a Transient Interest Rate Peg." Working Paper, Federal Reserve Bank of Cleveland.

Contessi, Silvio and Li Li (2013a): "Forward Guidance 101A: A Roadmap of the U.S. Experience." Federal Reserve Bank of St. Louis, Economic Synopses, no. 25: 1-3.

Contessi, Silvio and Li Li (2013b): “Forward Guidance 101B: A Roadmap of the International Experience." Federal Reserve Bank of St. Louis, Economic Synopses, no. 28: 1-4.

Del Negro, Marco, Marc Giannoni and Christina Patterson (2013): "The Forward Guidance Puzzle." Federal Reserve Bank of New York Staff Papers Number 574. 
Eggertsson, Gauti B. and Michael Woodford (2003): “The Zero Bound on Interest Rates and Optimal Monetary Policy." Brookings Papers on Economic Activity, vol. 1: 139-211.

Eichenbaum, Martin and Charles L. Evans (1995): "Some Empirical Evidence on the Effects of Shocks to Monetary Policy on Exchange Rates." The Quarterly Journal of Economics, vol. 110 (4): 975-1009.

Estrella, Arturo and Mishkin, Frederic S. (1998): “Predicting U.S. Recessions: Financial Variables as Leading Indicators." The Review of Economics and Statistics, vol. 80 (1): 45-61.

Filardo, Andrew and Boris Hofmann (2014): "Forward Guidance at the Zero Lower Bound." BIS Quarterly Review, March 2014: 37-53.

Giordani, Paolo (2004): "An Alternative Explanation of the Price Puzzle." Journal of Monetary Economics, vol. 51 (6): 1271-1296.

Hamilton, James D., Ethan S. Harris, Jan Hatzius and Kenneth D. West (2015): “The Equilibrium Real Funds Rate: Past, Present and Future." Mimeo, University of California-San Diego.

Holtz, Eakin D., W. Newey, and H. Rosen (1988). “Estimating Vector Autoregression with Panel Data." Econometrica, vol. 56 (6): 1371-1395.

Joyce, Michael A. S., Lasaosa, Ana, Stevens, Ibrahim and Long, Matthew (2011): “The Financial Market Impact of Quantitative Easing in the United Kingdom." International Journal of Central Banking, vol. 7 (3): 113-161. 
Krugman, Paul R. (2000): “Thinking about the Liquidity Trap." Journal of Japanese and International Economics, vol. 14 (4): 221-237.

Leduc, Sylvain and Keith Sill (2013): “Expectations and Economic Fluctuations: An Analysis Using Survey Data." The Quarterly Review of Economics and Statistics, vol. 95 (4): 1352-1367.

Lo, Stephanie and Kenneth Rogoff (2015): “Secular Stagnation, Debt Overhang and Other Rationales for Sluggish Growth, Six Years On." BIS Working Paper No. 482.

Love, Inessa and Lea Zicchino (2006): “Financial Development and Dynamic Investment Behavior: Evidence from a Panel VAR." The Quarterly Review of Economics and Finance, vol. 46 (2): 190-210.

Lucas, Robert E., Jr. and Prescott, Edward C. (1971): "Investment Under Uncertainty." Econometrica, vol. 39 (5): 659-681.

Rudebusch, Glenn D. and John C. Williams (2009): "Forecasting Recessions: The Puzzle of the Enduring Power of the Yield Curve." Journal of Business and Economic Statistics, vol. 27 (4): 492-503.

Sims, Christopher A. (1992): "Interpreting the Macroeconomic Time Series Facts: The Effects of Monetary Policy." European Economic Review, vol. 36 (5): 975-1000.

Summers, Lawrence (2014): "U.S. Economic Prospects: Secular Stagnation, Hysteresis, and the Zero Lower Bound." Business Economics, vol. 49 (2): 65-73. 
Wu, Cynthia Jing and Xia, Fan Dora (2014): “Measuring the Macroeconomic Impact of Monetary Policy at the Zero Lower Bound." NBER Working Paper No. 20117. 


\section{Appendix}

FRB of Philadelphia's Survey of Professional Forecasters:

"tbill6" is the four quarter ahead nominal interest rate forecast on the three month Treasury bill. Samples 40-50 forecasters, between 1981:Q3 and 2014:Q3, at a quarterly frequency.

St. Louis Federal Reserve's FRED database:

Inflation rate (CPI), unemployment rate, Federal Funds rate, oil price, monetary base, non-borrowed reserves, 10 Year Treasury Bill. "unrate" is the civilian unemployment rate; "inflation" is the inflation rate calculated from CPI; "ffr" is the Federal Funds rate; "bogmbase" is the St. Louis Adjusted Monetary Base; "tenyeartreasury" is the yield on the 10 Year U.S. Treasury Bill; " $n b r$ " is the non-borrowed reserves of depository institutions; "slope" is the slope of the yield curve calculated by the authors

Wall St. Journal / Haver Analytics:

"oilprice" is crude oil price per barrel, West Texas Intermediate

Federal Reserve Board of Governors:

"nomxchange" is the nominal trade-weighted value of U.S. dollar

(https://research.stlouisfed.org/fred2/series/TWEXBMTH)

Federal Reserve Bank of Atlanta:

"shadowrate" is the shadow Federal Funds rate (Wu and Xia (2014)) 
FRB of Philadelphia's Livingston Survey:

"tbill6" is the four quarter ahead nominal interest rate forecast on the three month Treasury bill. Between June 1992 and December 2014, at semiannual frequency.

Control for individual fixed effects with Helmert transformation:

Forward mean differencing removes mean of all future observations for each individual forecasters-time pair. Gives larger weight to observations closer to the beginning of the series (and assumes observations have equal variances).

$$
Z_{j t}^{H}=\sqrt{\frac{T-t}{T-t+1}}\left(Z_{j t}-\frac{1}{T-t} \sum_{z=t+1}^{T} Z_{j z}\right) .
$$


Table 1 - Data

\begin{tabular}{|c|c|c|c|}
\hline Label & Description & Source & Comments \\
\hline $\mathrm{i}_{1 \mathrm{t}+4 \mathrm{It}}^{\mathrm{e}}(\mathrm{j})$ & Expected short-term rate & SPF & $\begin{array}{l}\text { Forecasts } 4 \text { quarters ahead of the 3-month } \\
\text { T-bill (annualized rates, \%) for a sample of } \\
40-50 \text { forecasters each quarter }\end{array}$ \\
\hline $\mathrm{i}_{1 \mathrm{t}+41 \mathrm{t}}^{\mathrm{e}}(\mathrm{k})$ & Expected short-term rate & FRB.P & $\begin{array}{l}\text { Forecasts } 4 \text { quarters ahead of the 3-month } \\
\text { T-bill (annualized rates, \%) for a sample of } \\
\text { around } 50 \text { forecasters each semester }\end{array}$ \\
\hline $\mathrm{i}_{10 y e a r}$ & 10 Year Treasury Bill & FRED & $\begin{array}{l}\text { Yield on the U.S. } 10 \text { Year Treasury Bill } \\
\text { (annualized rate, \%) }\end{array}$ \\
\hline$\pi_{\mathrm{t}}$ & Inflation Rate (CPI) & FRED & $\begin{array}{l}\text { Seasonally-adjusted, quarter-over-quarter } \\
(\%)\end{array}$ \\
\hline$M_{t}^{0}$ & Monetary Base & FRED & $\begin{array}{l}\text { St. Louis Fed' Adjusted Monetary Base, } \\
\text { quarter-over-quarter (\%) }\end{array}$ \\
\hline $\mathrm{O}_{\mathrm{t}}$ & Oil Price & WSJ & $\begin{array}{l}\text { Spot crude oil price: West Texas } \\
\text { Intermediate, quarter-over-quarter (\%) }\end{array}$ \\
\hline$u_{t}$ & Unemployment Rate & FRED & Seasonally-adjusted (\%) \\
\hline $\mathrm{i}_{\mathrm{t}}$ & Fed Funds Rate & FRED & Annualized rate (\%) \\
\hline$\Delta \mathrm{e}_{\mathrm{t}}$ & $\begin{array}{l}\text { Broad Nominal Trade } \\
\text { Weighted Value of the } \\
\text { Dollar }\end{array}$ & FRB & $\begin{array}{l}\text { Against the } 36 \text { major trading partners of } \\
\text { the U.S., quarter-over-quarter (\%) }\end{array}$ \\
\hline$\Delta \mathrm{NBR}_{\mathrm{t}}$ & Non-Borrowed Reserves & FRED & $\begin{array}{l}\text { Non-borrowed reserves of depository } \\
\text { institutions, quarter-over-quarter (\%) }\end{array}$ \\
\hline spread $_{t}$ & Yield Curve Slope & FRED & $\begin{array}{l}\text { Short-term rate (FFR) subtracted from } \\
\text { yield on } 10 \text { Year Treasury Bill }\end{array}$ \\
\hline$i_{t}^{s}$ & $\begin{array}{l}\text { Shadow Federal Funds } \\
\text { rate }\end{array}$ & FRB.A & Wu and Xia (2014) (annualized rate, \%) \\
\hline
\end{tabular}

Note: All data calculated by the authors are available upon request. This data or a subset is included in the vector of variables $z_{\mathrm{j} t}$. The acronym SPF stands for the Survey of Professional Forecasters; WSJ stands for Wall St. Journal / Haver Analytics; FRED stands for Federal Reserve Economic Data of the Federal Reserve Bank of St. Louis; FRB stands for Federal Reserve Board; FRB.P stands for Federal Reserve Bank of Philadelphia, Livingston Survey; FRB.A stands for Federal Reserve Bank of Atlanta.

Note: The (broad) nominal trade-weighted value of the dollar is a weighted average of the foreign exchange value of the U.S. dollar against the currencies of a broad group of major U.S. trading partners. An increase in the tradevalue of the dollar is interpreted as an appreciation of the U.S. dollar. 
Data: 1981-2014

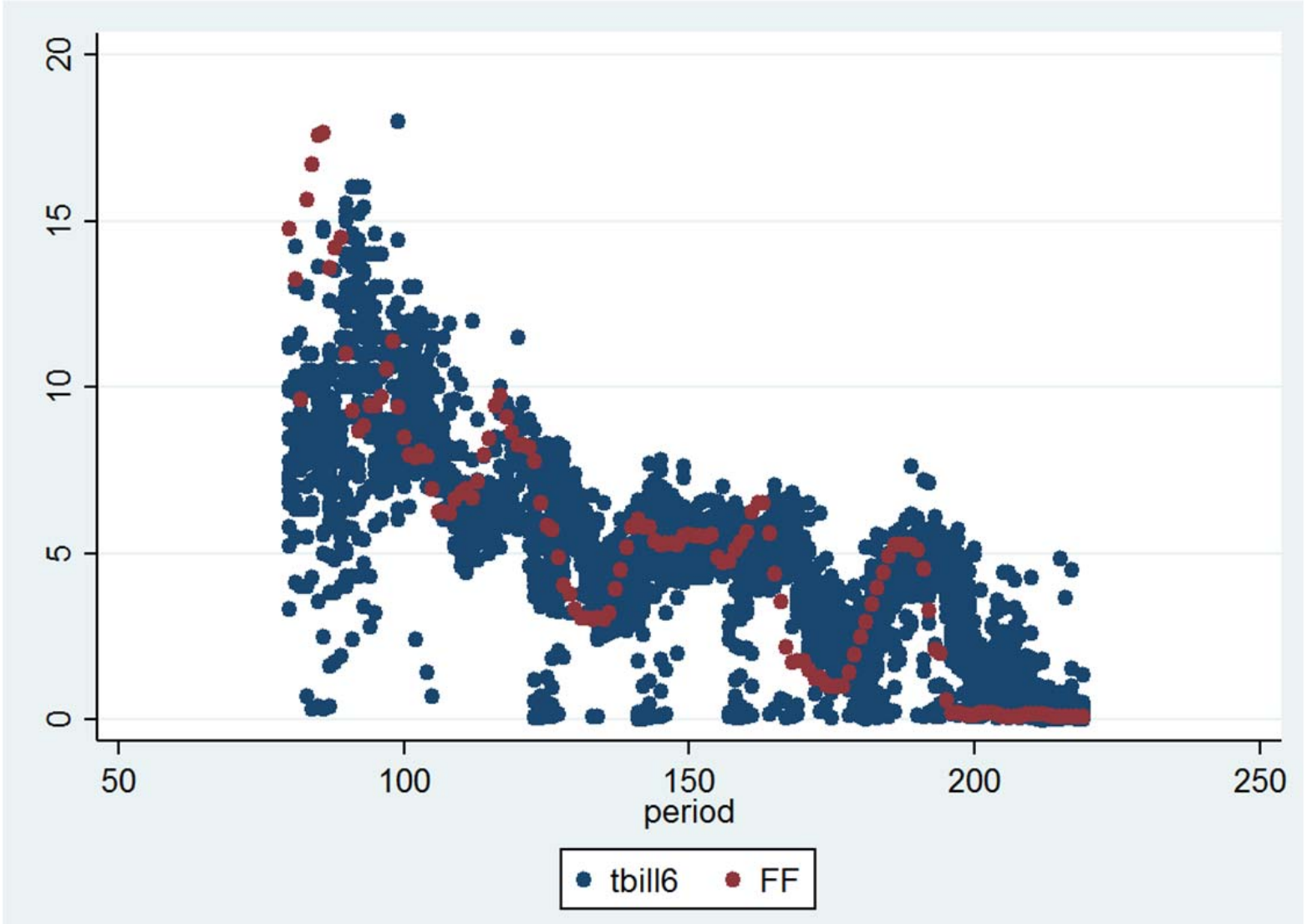

Figure 1: Expected interest rate on 3 month Treasury and actual Federal Funds rate, time adjusted for 4 quarter lag on expectations variable 


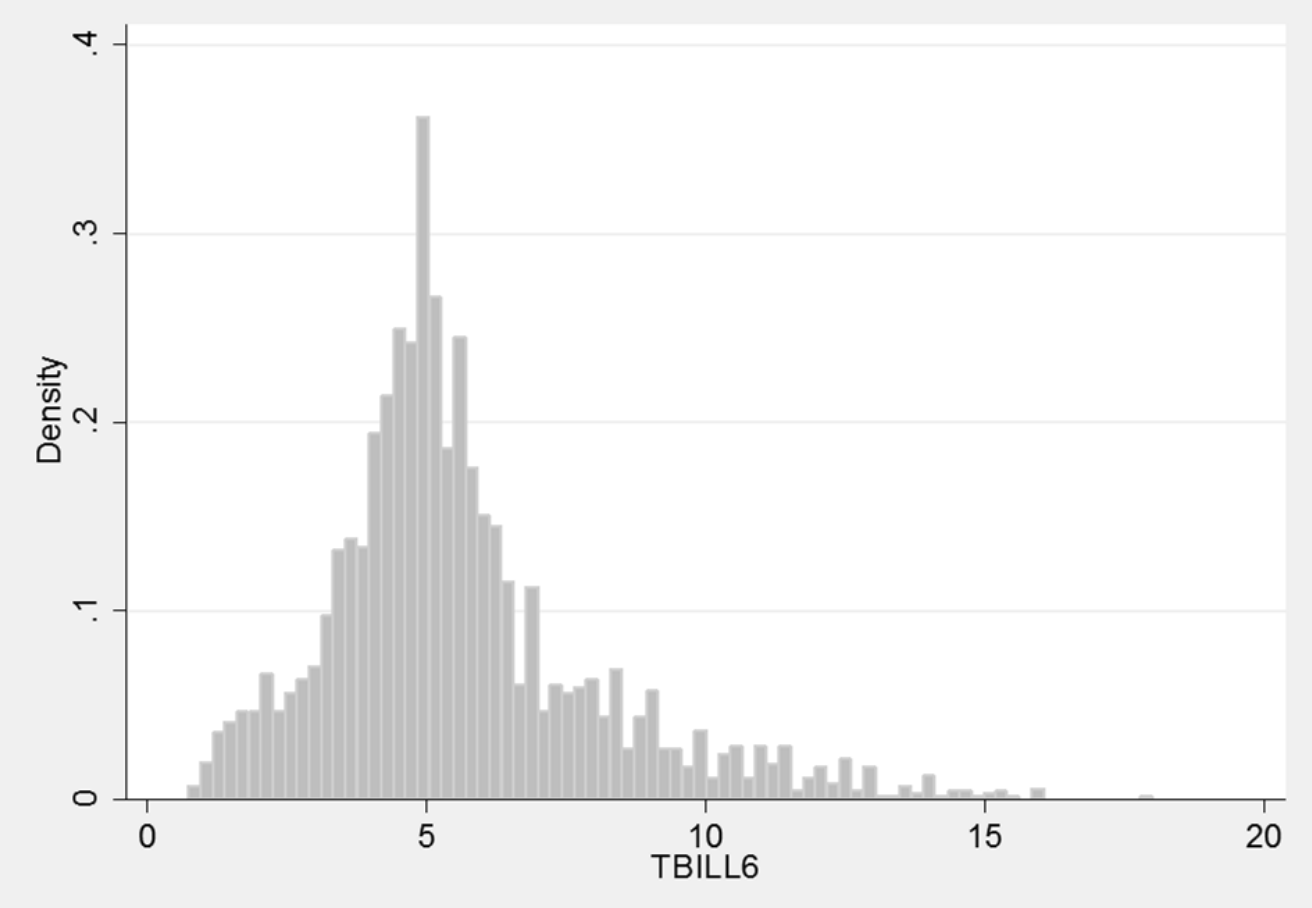

Figure 2: Distribution of expected nominal rate on 3-month Treasury (1981:Q3-2008:Q1)

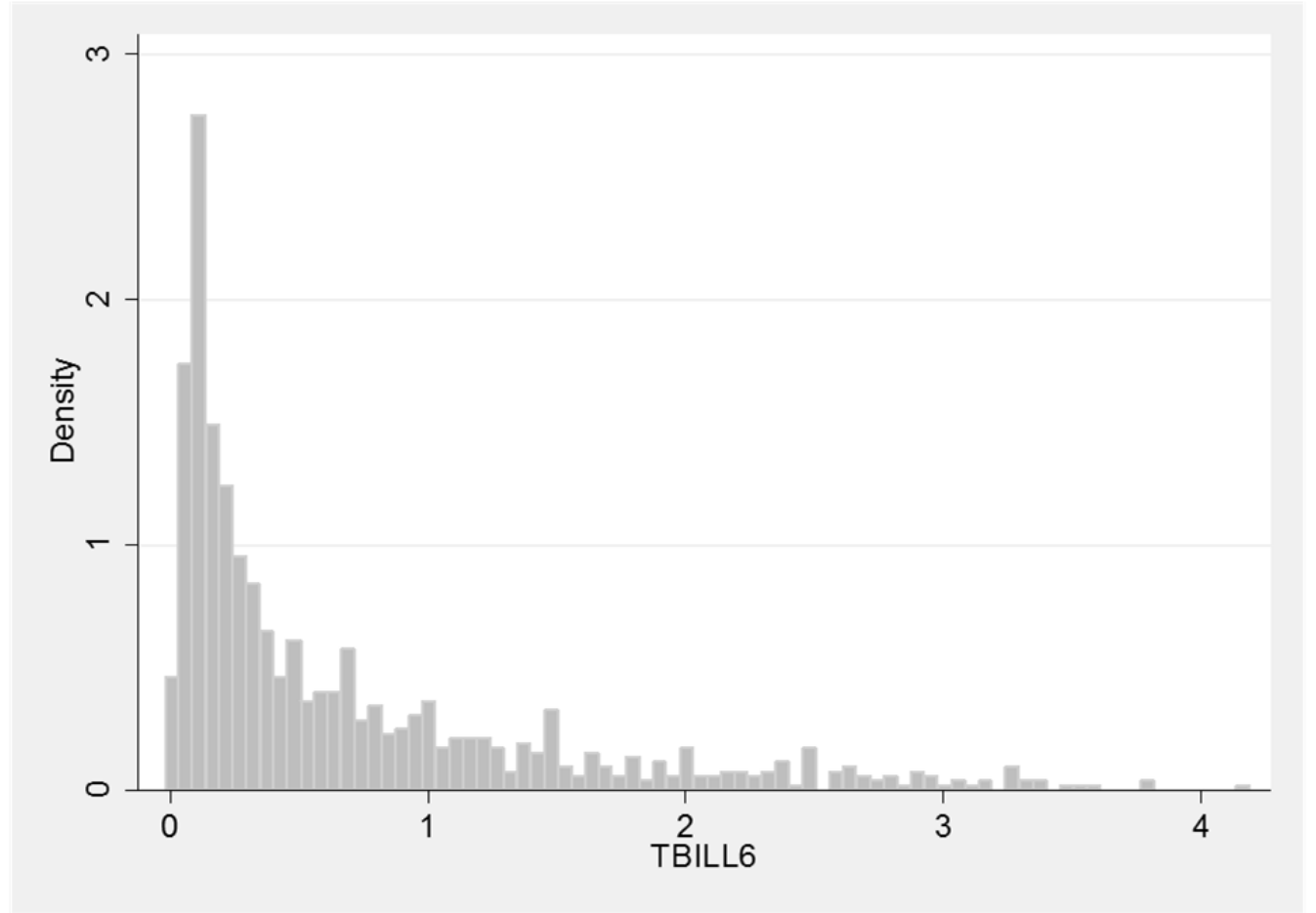

Figure 3: Distribution of expected nominal rate on 3-month Treasury (2008:Q2-2014:Q3) 


\section{Benchmark Model}

\begin{tabular}{|c|c|c|c|}
\hline & Coefficient & Standard Error & $\mathrm{t}$-statistic \\
\hline \multicolumn{4}{|c|}{ Interest rate expectations (tbill6) } \\
\hline L.tbill6 & 0.682309 & 0.030284 & 22.529973 \\
\hline L.inflation & 0.033578 & 0.048585 & 0.691113 \\
\hline L.un_rate & -0.038315 & 0.018182 & -2.107228 \\
\hline L.FFR & 0.117888 & 0.024900 & 4.734563 \\
\hline \multicolumn{4}{|l|}{ Inflation rate } \\
\hline L.tbill6 & 0.001636 & 0.011487 & 0.142451 \\
\hline L.inflation & 0.069937 & 0.023331 & 2.997641 \\
\hline L.un_rate & -0.047319 & 0.009513 & -4.974212 \\
\hline L.FFR & 0.032041 & 0.009808 & 3.266844 \\
\hline \multicolumn{4}{|c|}{ Unemployment rate } \\
\hline L.tbill6 & -0.014650 & 0.010012 & -1.463232 \\
\hline L.inflation & 0.075282 & 0.014529 & 5.181543 \\
\hline L.un_rate & 0.978693 & 0.007234 & 135.293080 \\
\hline L.FFR & 0.039644 & 0.007563 & 5.241570 \\
\hline \multicolumn{4}{|c|}{ Federal Funds rate } \\
\hline L.tbill6 & 0.221293 & 0.028843 & 7.672243 \\
\hline L.inflation & -0.185133 & 0.046277 & -4.000550 \\
\hline L.un_rate & -0.125762 & 0.014215 & -8.847077 \\
\hline L.FFR & 0.738186 & 0.025240 & 29.247078 \\
\hline \multicolumn{4}{|c|}{ Results of the estimation by system GMM } \\
\hline
\end{tabular}

Figure 4: Panel VAR model output (1981:Q3-2008:Q1) 


\begin{tabular}{lccc}
\hline & Coefficient & Standard Error & t-statistic \\
\hline Interest rate expectations (tbill6) & & & \\
L.tbill6 & 0.610101 & 0.061456 & 9.927512 \\
L.inflation & 0.059232 & 0.020138 & 2.941328 \\
L.un_rate & 0.057302 & 0.009936 & 5.767405 \\
L.FFR & 0.156564 & 0.084338 & 1.856385 \\
\hline & & & \\
\hline Inflation rate & & & \\
L.tbill6 & -0.234919 & 0.071918 & -3.266495 \\
L.inflation & 0.250847 & 0.021842 & 11.484348 \\
L.un_rate & 0.070058 & 0.014533 & 4.820496 \\
L.FFR & -0.219793 & 0.155041 & -1.417642 \\
\hline & & & \\
\hline Unemployment rate & & & 3.690546 \\
L.tbill6 & 0.094407 & 0.025581 & -30.309197 \\
L.inflation & -0.374041 & 0.012341 & 113.551220 \\
L.un_rate & 0.996458 & 0.008775 & 14.852605 \\
L.FFR & 0.533765 & 0.035937 & \\
\hline & & & -2.158226 \\
\hline Federal Funds rate & & 0.0268329 \\
L.tbill6 & -0.051846 & 0.008017 & 1.969846 \\
L.inflation & 0.018186 & 0.003551 & \\
L.un_rate & 0.006995 & 0.052446 & \\
L.FFR & 0.650349 & GMM & \\
\hline & & & \\
\hline
\end{tabular}

Figure 5: Panel VAR model output (2008:Q2-2014:Q3) 


\begin{tabular}{llllll|}
\hline \multicolumn{1}{c}{ Parameter } & Period & Interest rate expectations (tbill6) & Inflation rate & Unemployment rate & Federal Funds rate \\
\hline Interest rate expectations (tbill6) - Non ZLB & 4 & 0.977066 & 0.000294 & 0.008195 \\
Interest rate expectations (tbill6) - ZLB & 4 & 0.973417 & 0.021034 & 0.002322 & 0.003227 \\
\hline Inflation rate - Non ZLB & 4 & 0.027908 & 0.962730 & 0.006480 & 0.002883 \\
Inflation rate - ZLB & 4 & 0.238670 & 0.755750 & 0.003863 & 0.001717 \\
\hline Unemployment rate - Non ZLB & 4 & 0.118393 & 0.005543 & 0.860960 \\
Unemployment rate - ZLB & 4 & 0.076128 & 0.179542 & 0.665330 \\
\hline Federal Funds rate - Non ZLB & 4 & 0.493742 & 0.004097 & 0.126534 \\
Federal Funds rate - ZLB & 4 & 0.224465 & 0.555390 & 0.036243 \\
\hline
\end{tabular}

Percentage of variation in the row variable explained by column variable

\begin{tabular}{llccccc|}
\hline \multicolumn{1}{c}{ Parameter } & Period & Interest rate expectations & Inflation & Unemployment & Federal Funds \\
\hline Interest rate expectations - Non ZLB & 20 & 0.919487 & 0.000592 & 0.053862 & 0.026059 \\
Interest rate expectations - ZLB & 20 & 0.922222 & 0.020141 & 0.028635 & 0.029008 \\
\hline Inflation rate - Non ZLB & 20 & 0.035565 & 0.940683 & 0.020168 & 0.003584 \\
Inflation rate - ZLB & 20 & 0.240477 & 0.750361 & 0.006248 & 0.002915 \\
\hline Unemployment rate - Non ZLB & 20 & 0.073743 & 0.005336 & 0.816591 & 0.104330 \\
Unemployment rate - ZLB & 20 & 0.342002 & 0.035606 & 0.373720 \\
\hline Federal Funds rate - Non ZLB & 20 & 0.569371 & 0.000350 & 0.185940 \\
\hline Federal Funds rate - ZLB & 20 & 0.222187 & 0.556288 & 0.036088 \\
\hline
\end{tabular}

Percentage of variation in the row variable explained by column variable

Figure 6: Variance decomposition 

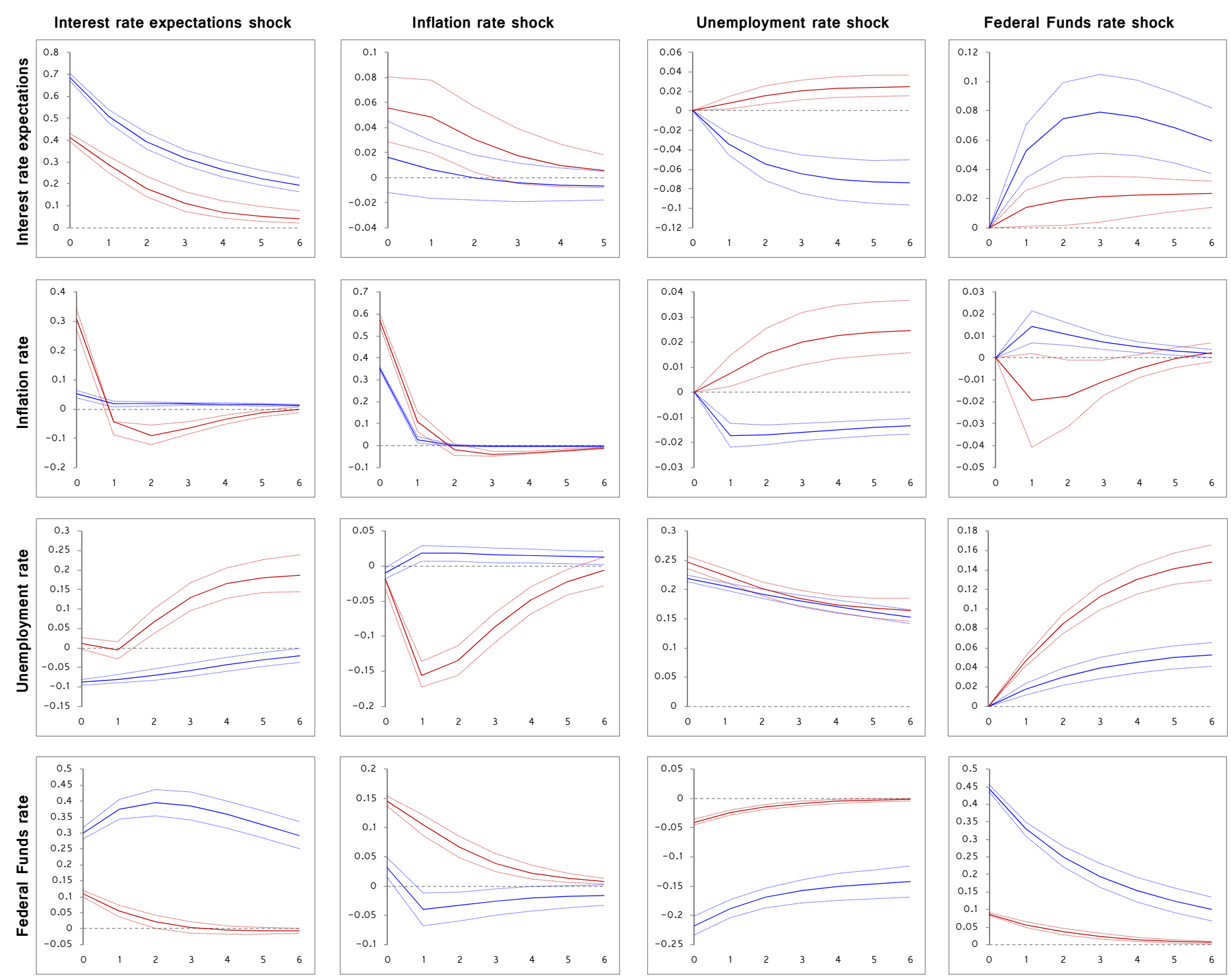

Figure 7a: Impulse Response Functions, 95\% confidence interval bands generated using 500 Monte Carlo simulations

Non ZLB ( 1981:Q3-2008:Q1)

ZLB ( 2008:Q2-2014:Q3 ) 

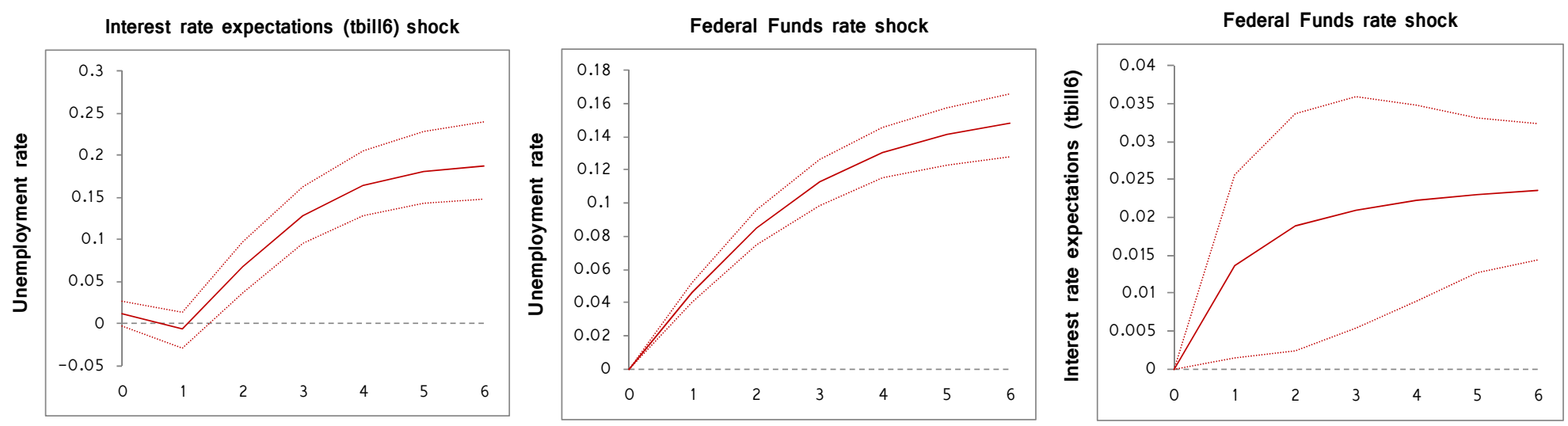

Figure 7b: Impulse Response Functions, using Federal Funds rate as monetary policy tool
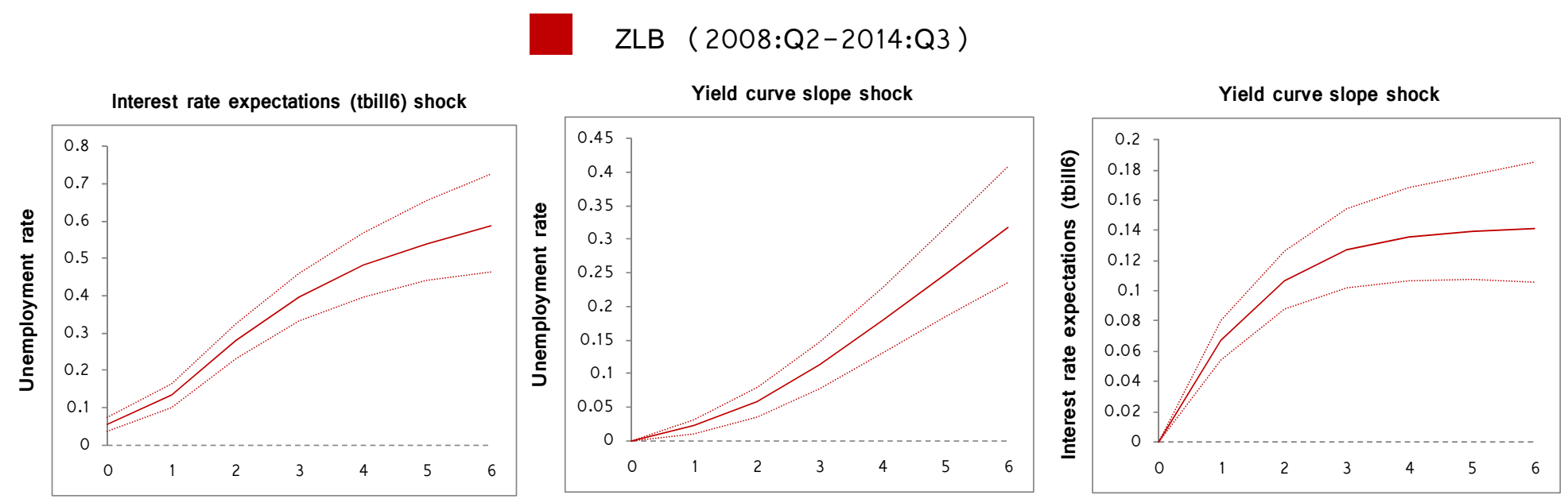

Figure 7c: Impulse Response Functions, using slope of the yield curve as monetary policy tool

ZLB (2008:Q2-2014:Q3)
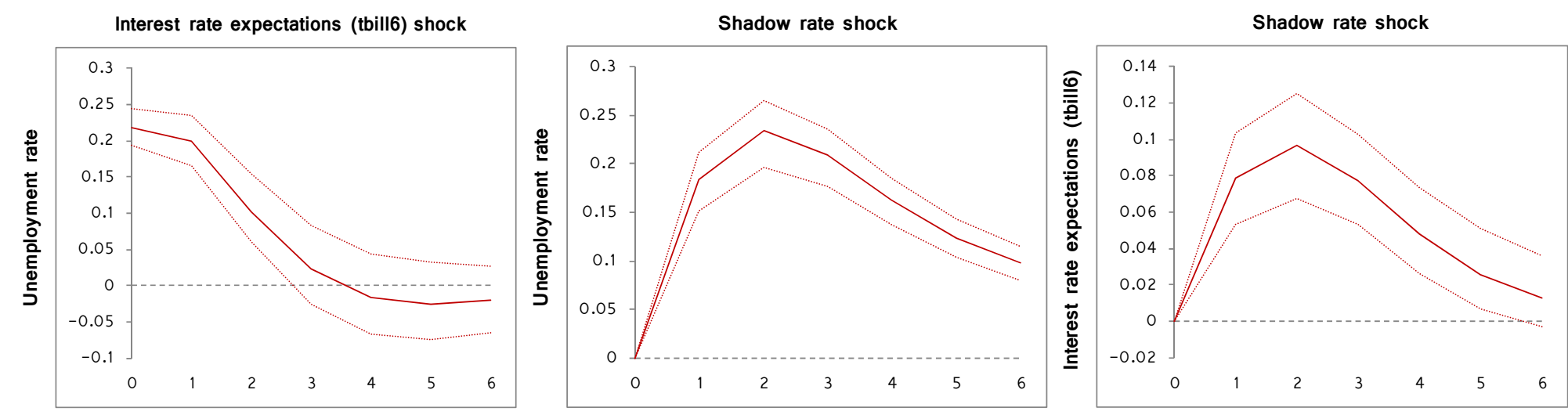

Figure 7d: Impulse Response Functions, using Shadow Rate as monetary policy tool

ZLB (2008:Q2-2014:Q3) 


\section{Augmented Models - Select Impulse Response Functions, 95\% Confidence Interval Bands}

\section{Generated using 500 Monte Carlo simulations}

Interest rate expectations (tbill6) shock

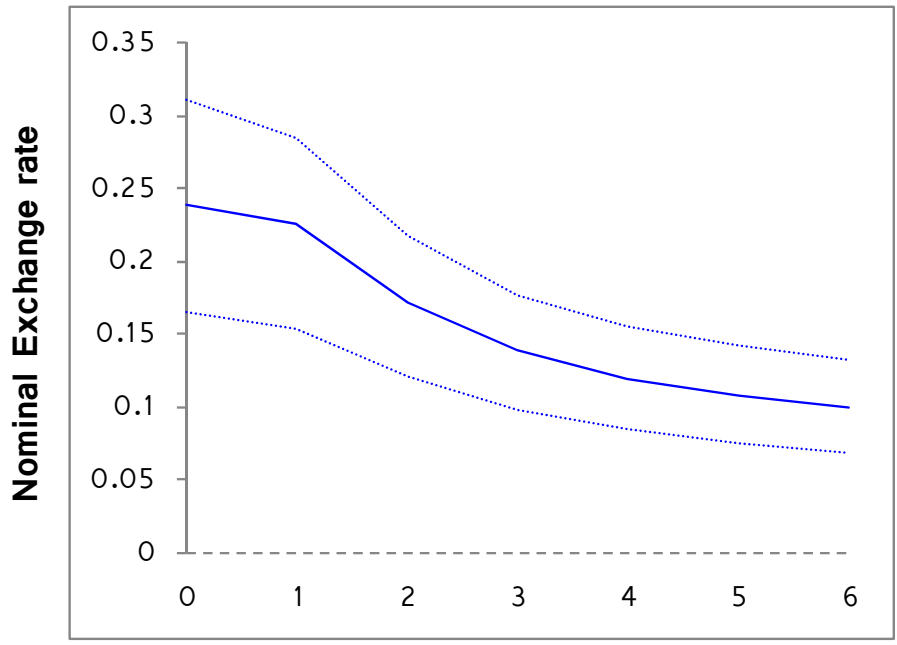

Non ZLB ( 1981:Q3-2008:Q1)
Interest rate expectations (tbill6) shock

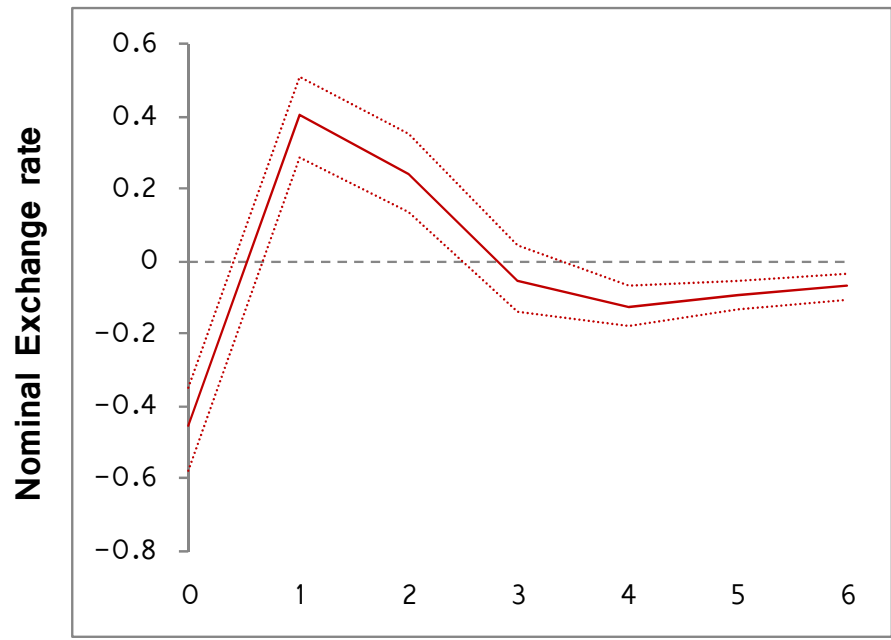

ZLB (2008:Q2-2014:Q3 )

Figure 8a: Addition of nominal exchange rate

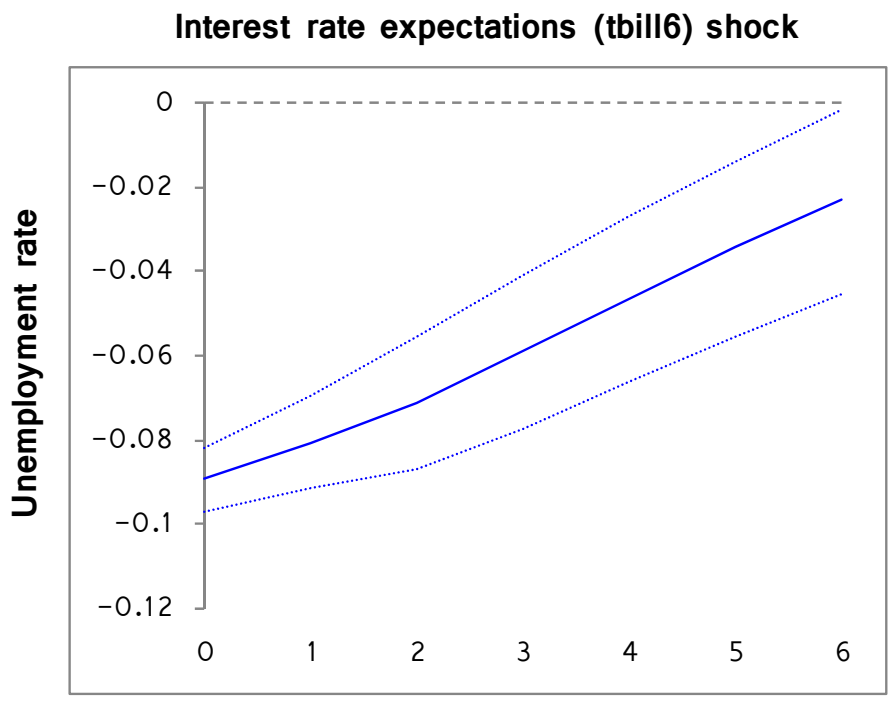

Non ZLB (1981:Q3-2008:Q1)
Interest rate expectations (tbill6) shock

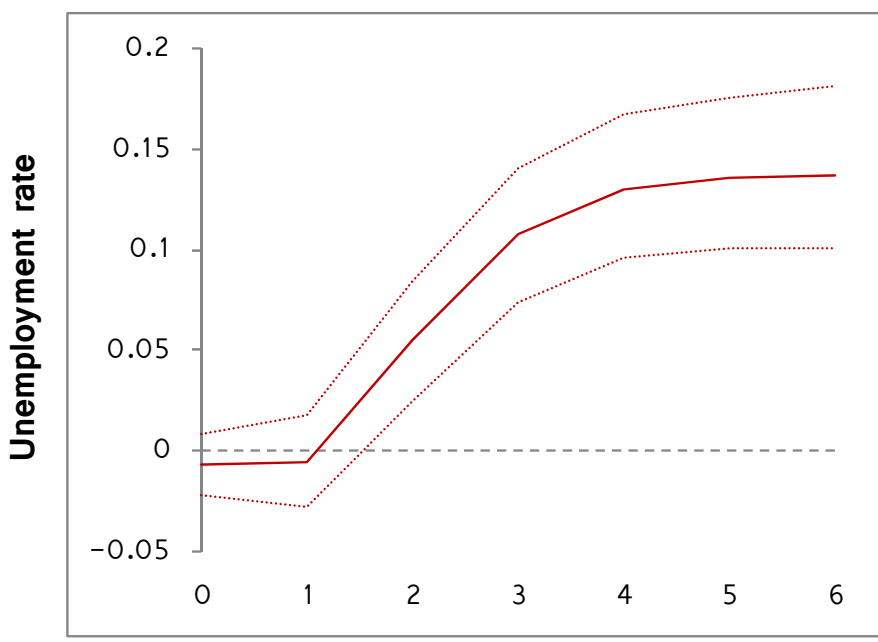

ZLB (2008:Q2-2014:Q3 )

Figure 8b: Addition of nominal exchange rate 

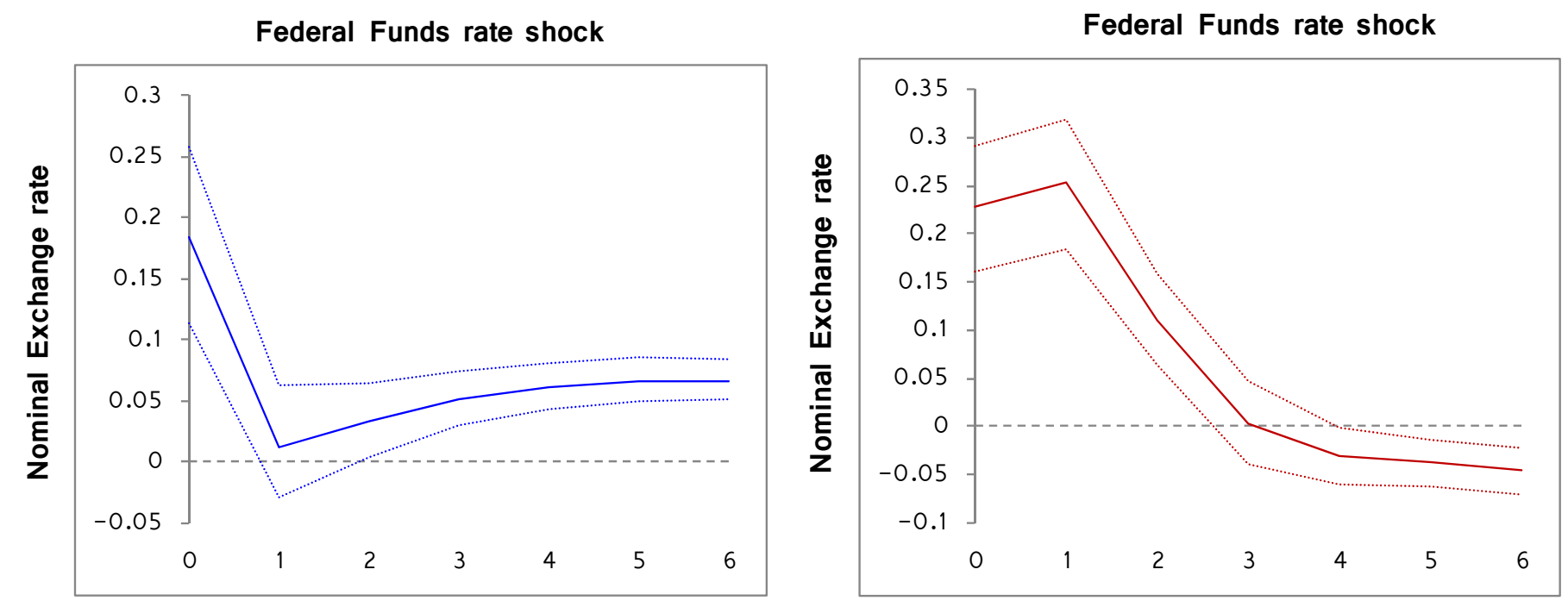

Figure 8c: Addition of nominal exchange rate

Non ZLB (1981:Q3-2008:Q1)

ZLB (2008:Q2-2014:Q3) 


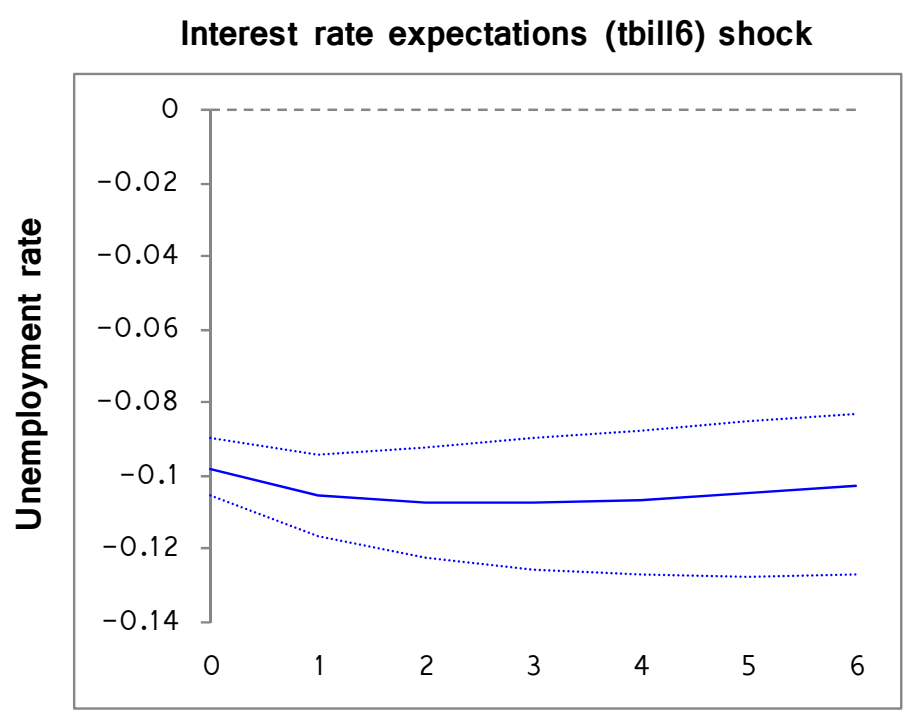

Non ZLB (1981:Q3-2008:Q1)
Interest rate expectations (tbill6) shock

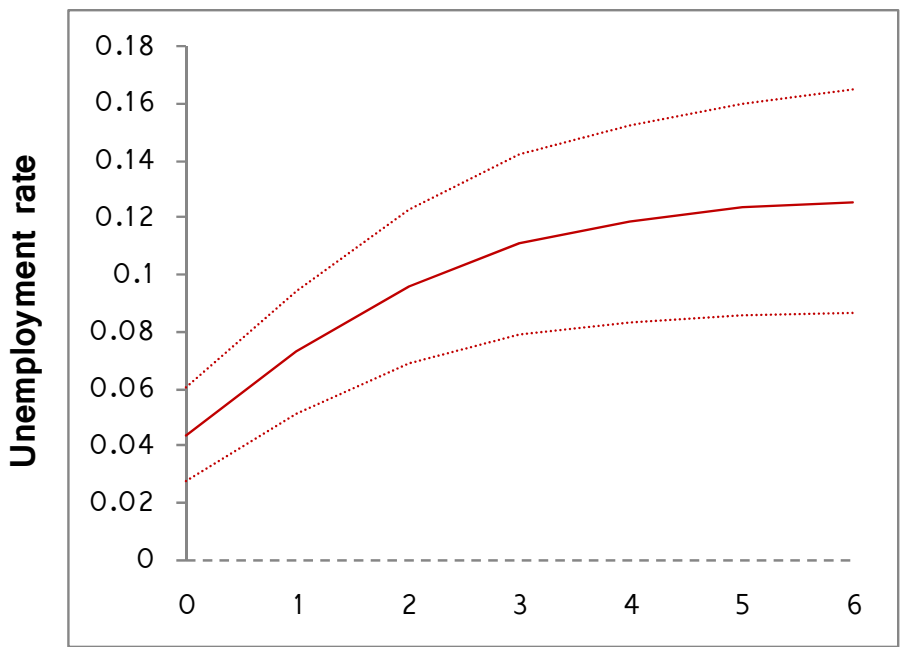

ZLB (2008:Q2-2014:Q3)

Figure 9a: Addition of exogenous oil price

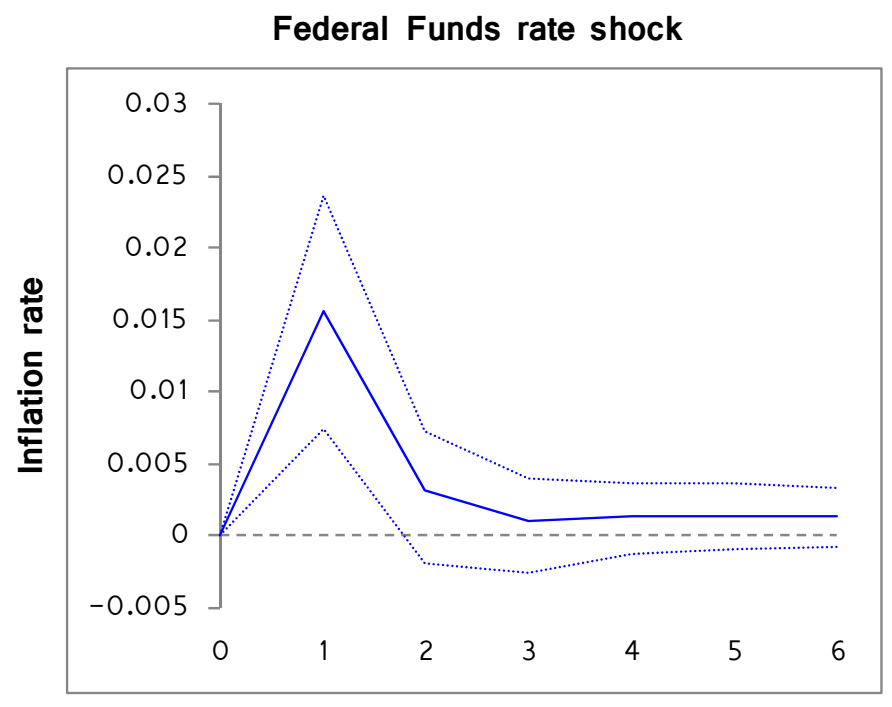

Non ZLB (1981:Q3-2008:Q1)

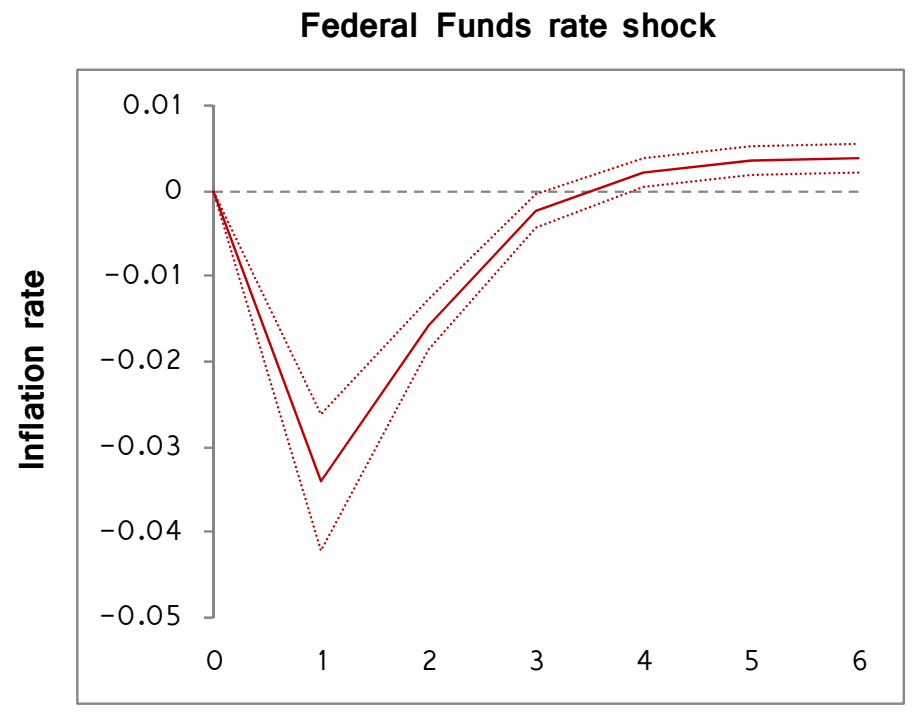

ZLB (2008:Q2-2014:Q3 )

Figure 9b: Addition of exogenous oil price 


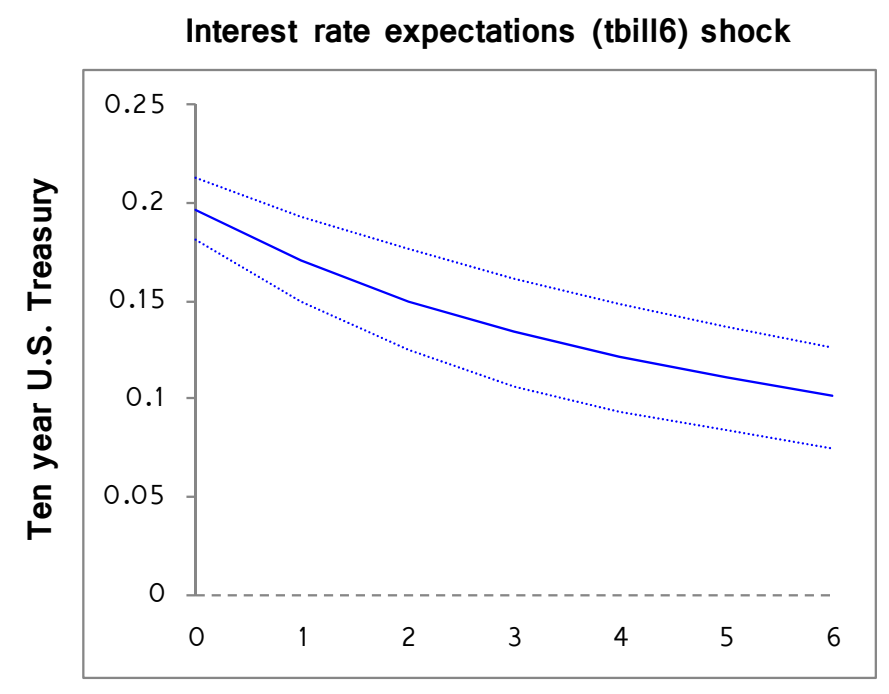

Non ZLB (1981:Q3-2008:Q1)

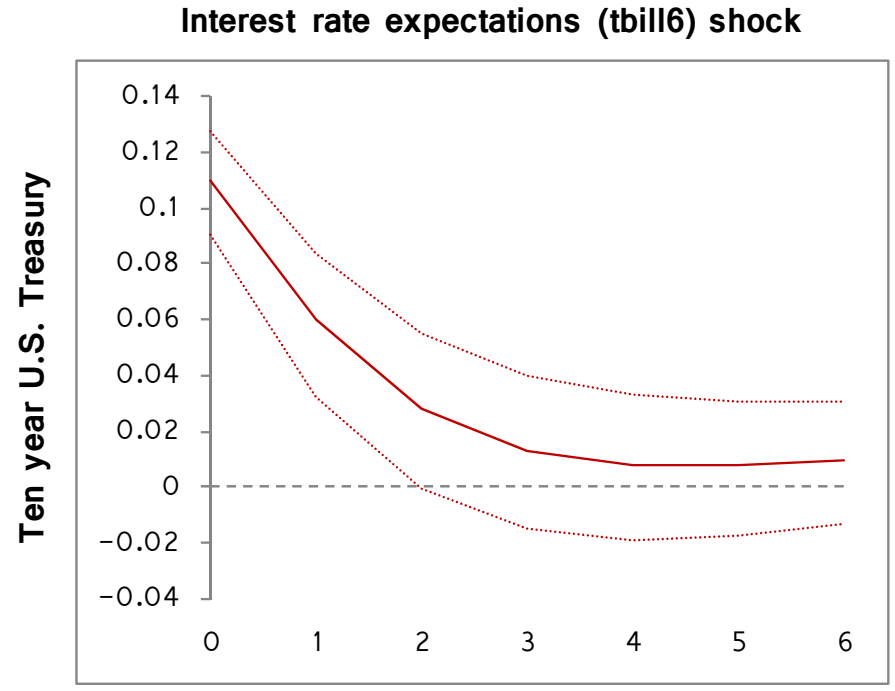

ZLB (2008:Q2-2014:Q3 )

Figure 10a: Addition of 10 Year U.S. Treasury Bill

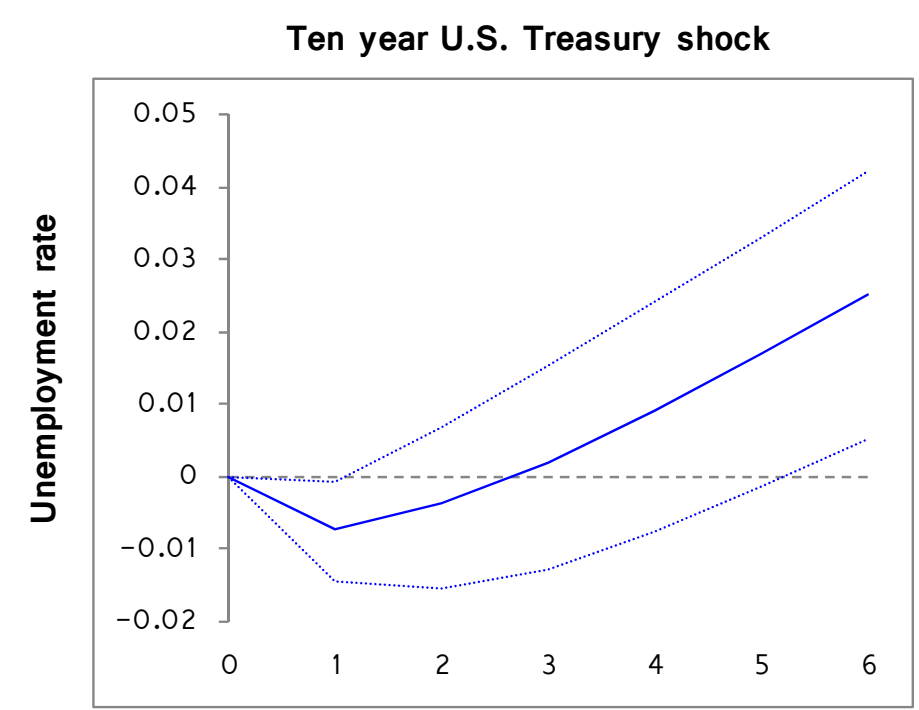

Non ZLB (1981:Q3-2008:Q1)
Ten year U.S. Treasury shock

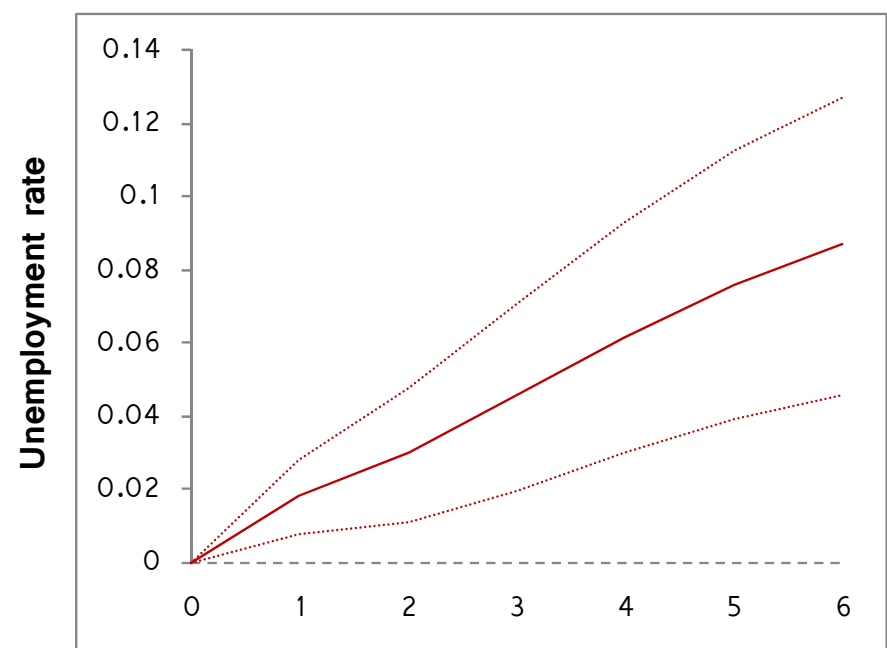

ZLB (2008:Q2-2014:Q3)

Figure 10b: Addition of 10 Year U.S. Treasury Bill 


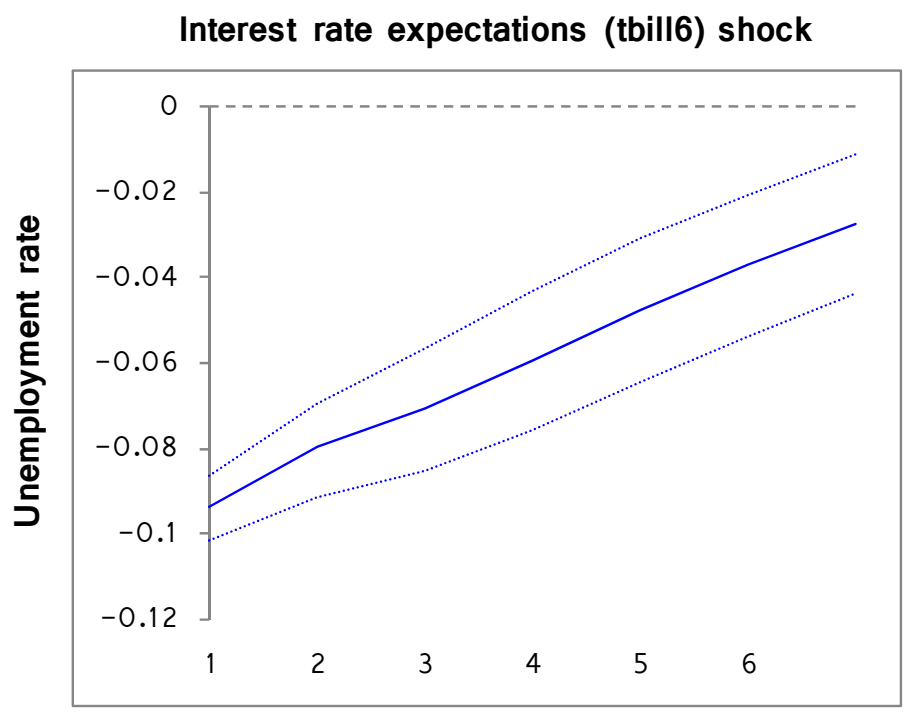

Non ZLB (1981:Q3-2008:Q1)

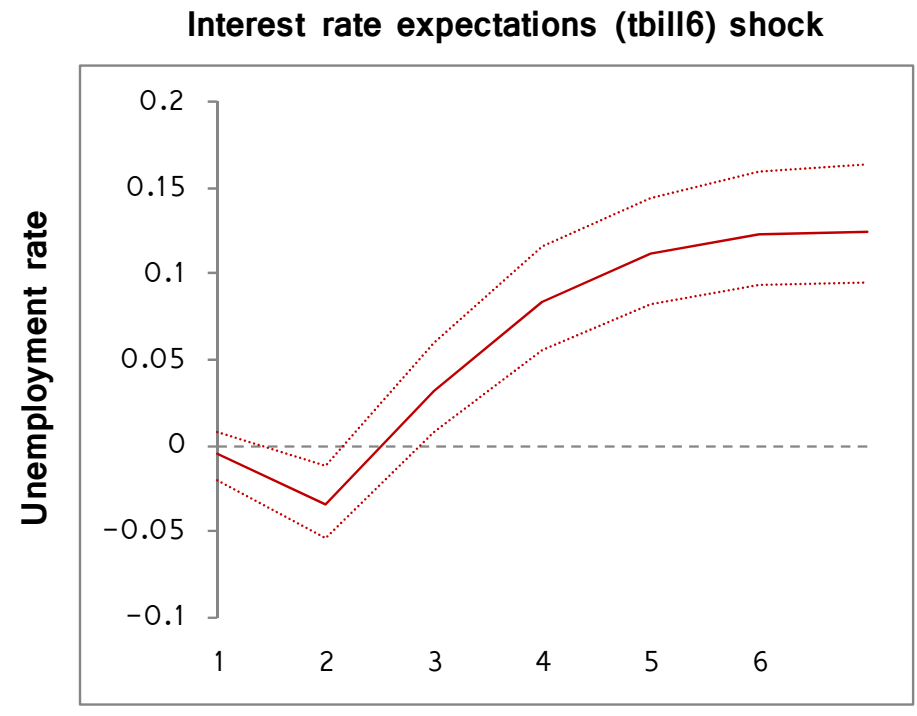

ZLB (2008:Q2-2014:Q3 )

Figure 10c: Addition of 10 Year U.S. Treasury Bill 


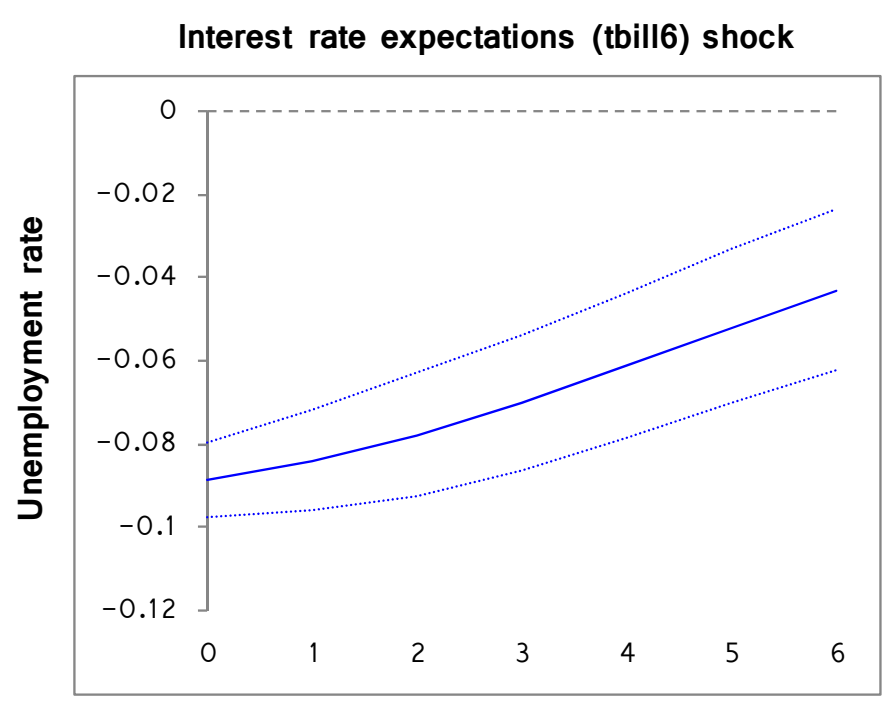

Non ZLB (1981:Q3-2008:Q1)

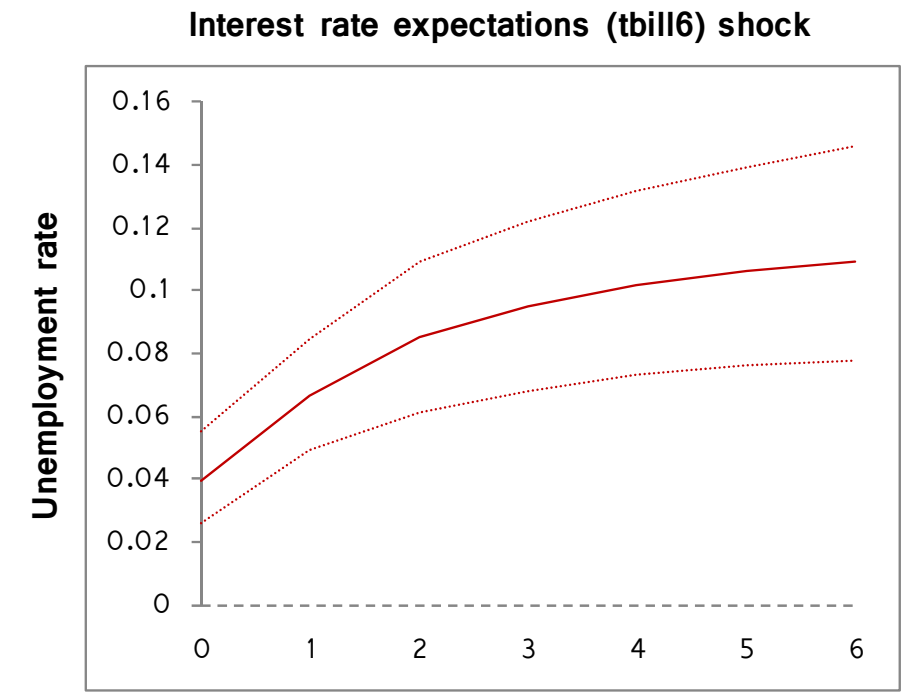

ZLB (2008:Q2-2014:Q3)

Figure 11a: Addition of exogenous monetary base

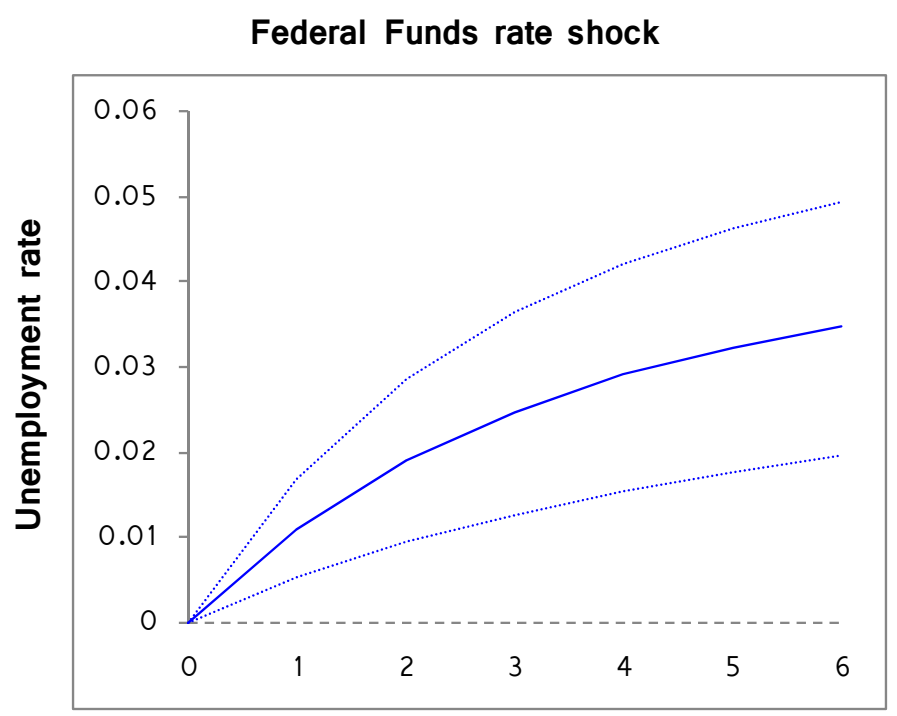

Non ZLB (1981:Q3-2008:Q1)

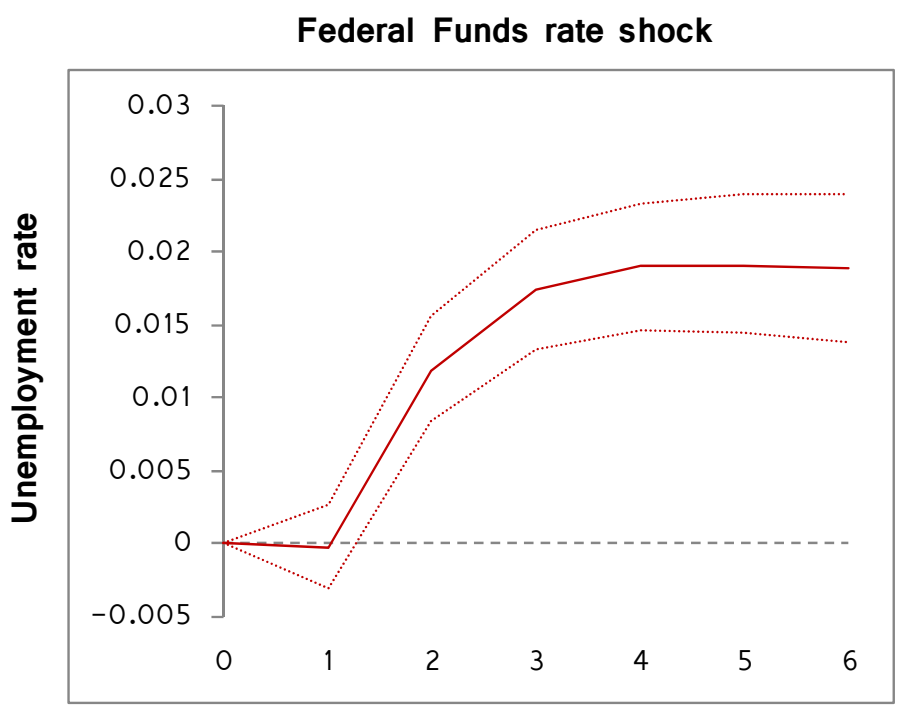

ZLB (2008:Q2-2014:Q3 )

Figure 11b: Addition of exogenous monetary base 


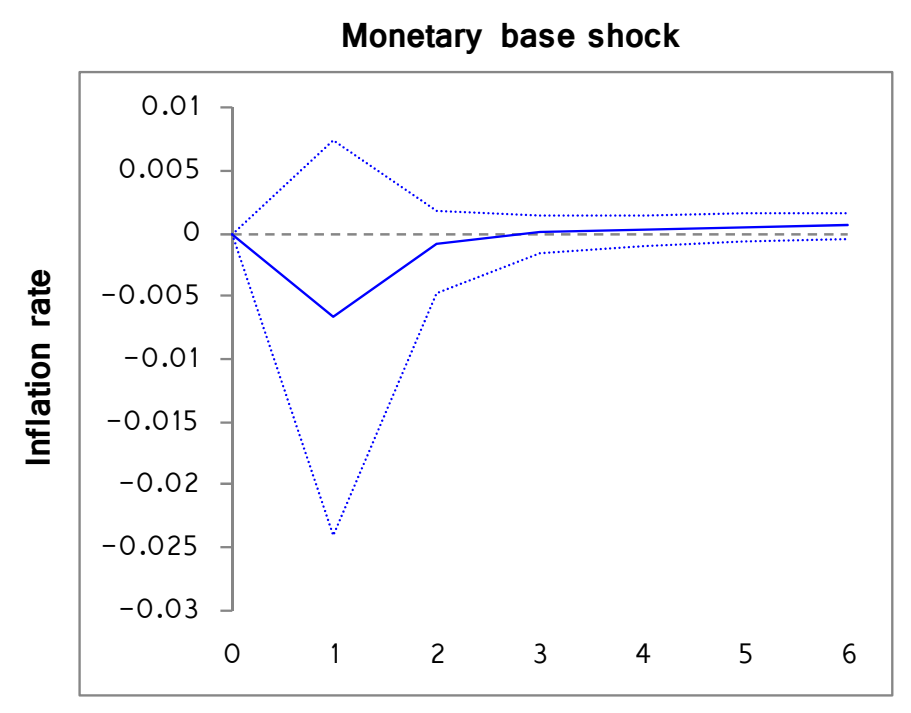

Non ZLB (1981:Q3-2008:Q1)

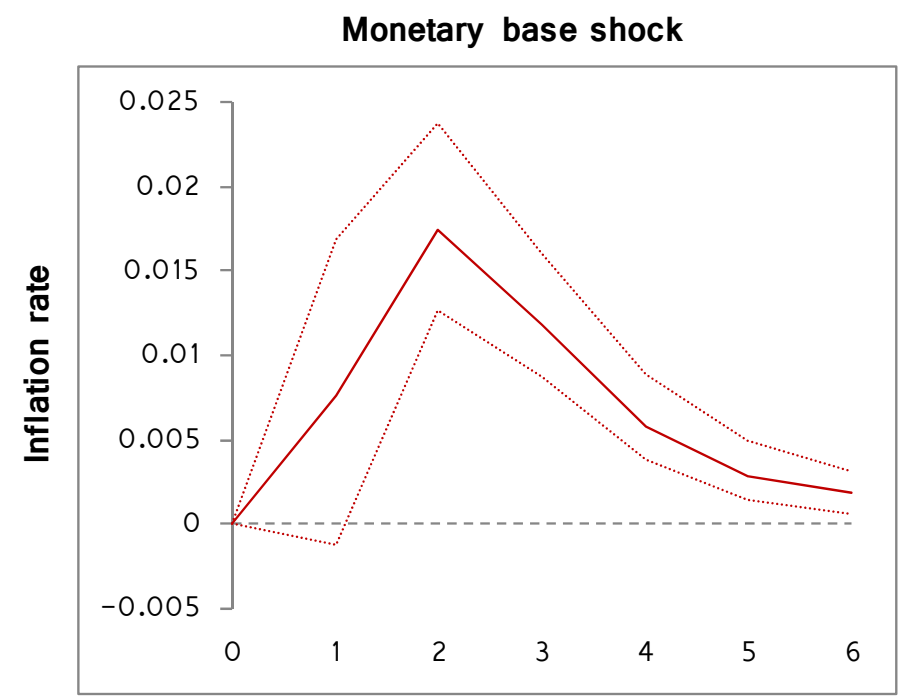

ZLB (2008:Q2-2014:Q3)

Figure 11c: Addition of exogenous monetary base

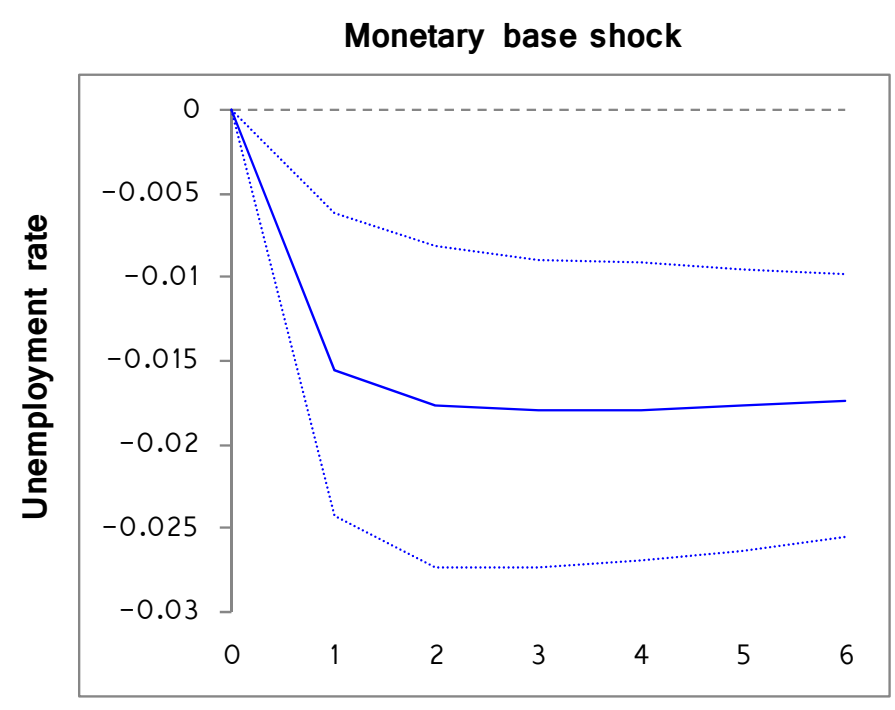

Non ZLB (1981:Q3-2008:Q1)

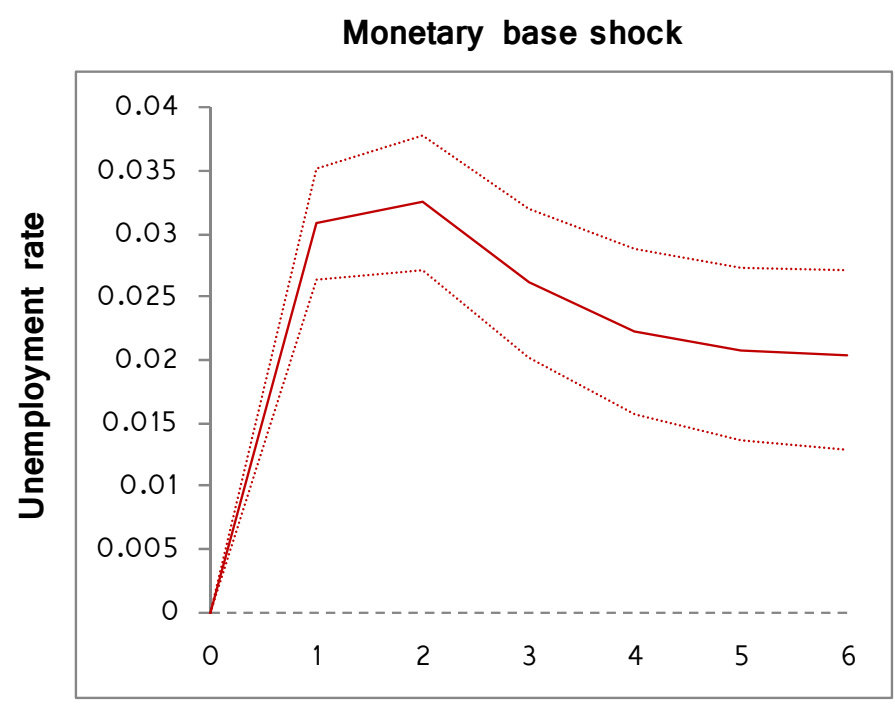

ZLB (2008:Q2-2014:Q3)

Figure 11d: Addition of exogenous monetary base 


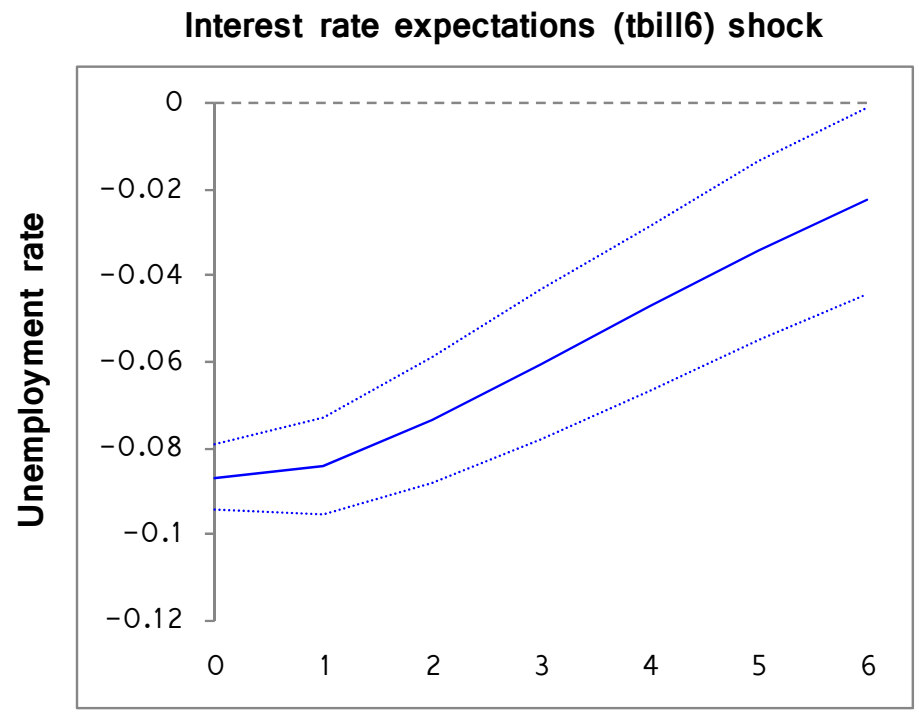

Non ZLB (1981:Q3-2008:Q1)

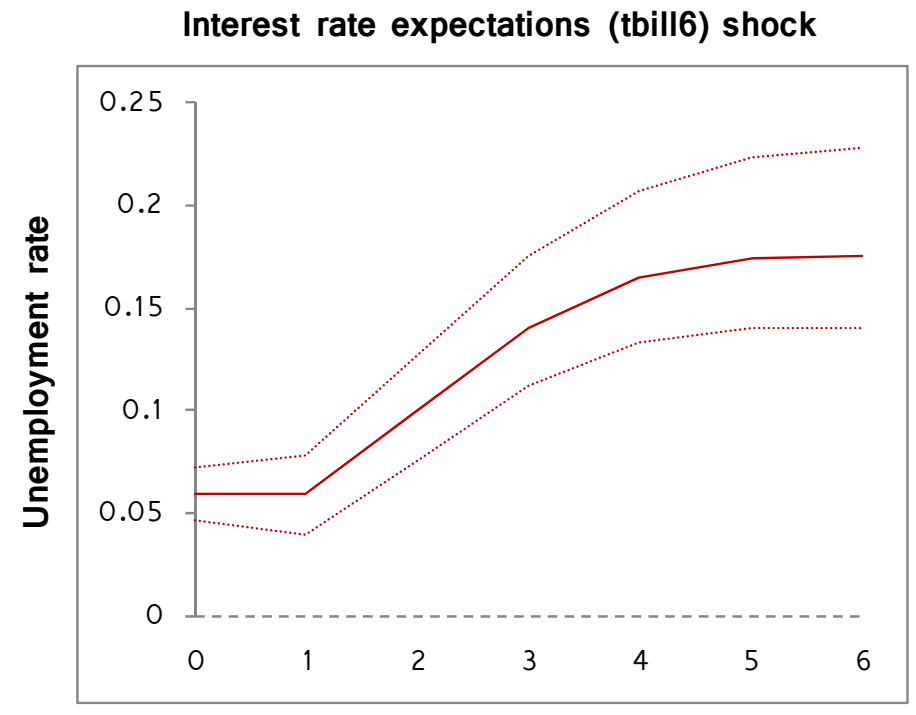

ZLB ( 2008:Q2-2014:Q3 )

Figure 12a: Addition of Non-Borrowed Reserves

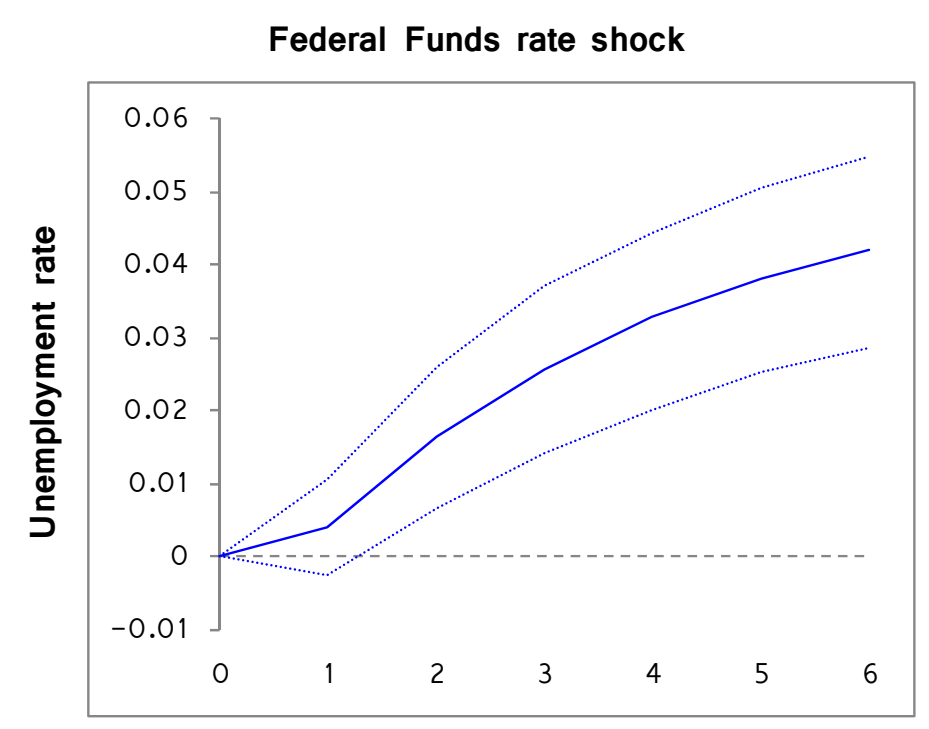

Non ZLB (1981:Q3-2008:Q1)

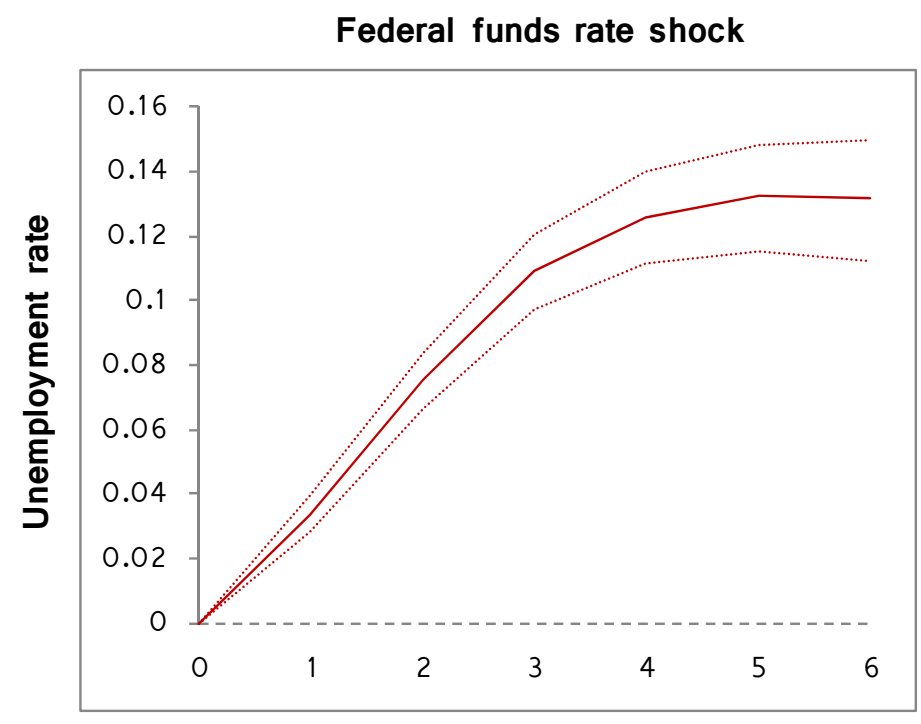

ZLB (2008:Q2-2014:Q3)

Figure 12b: Addition of Non-Borrowed Reserves 
Non-borrowed reserves shock

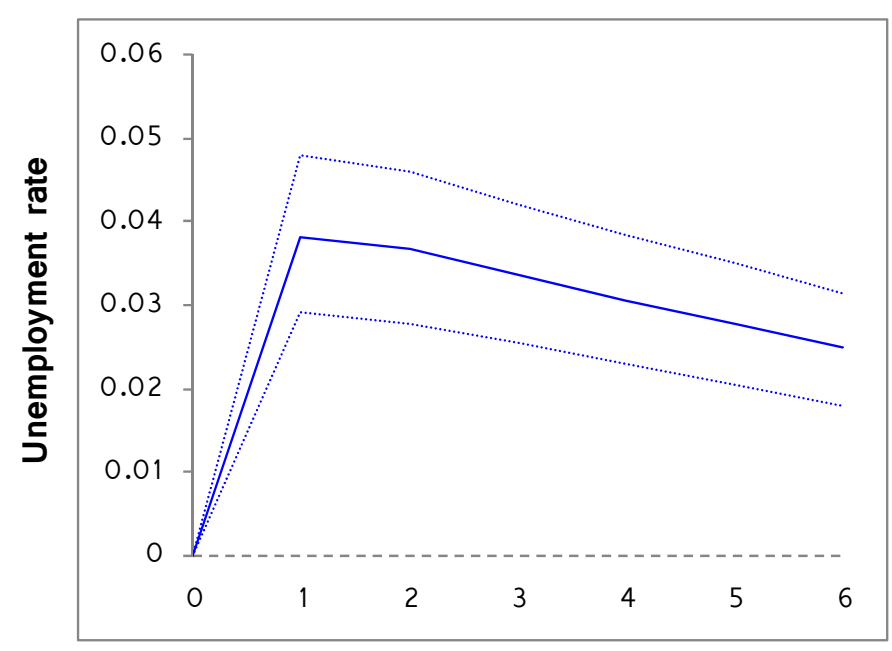

Non ZLB (1981:Q3-2008:Q1)
Non-borrowed reserves shock

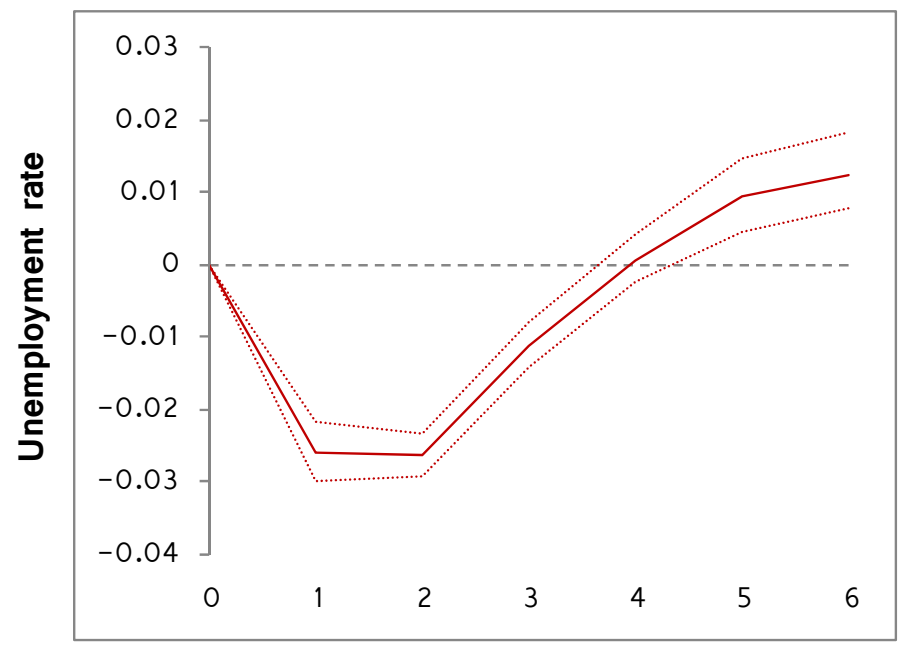

ZLB (2008:Q2-2014:Q3)

Figure 12c: Addition of Non-Borrowed Reserves

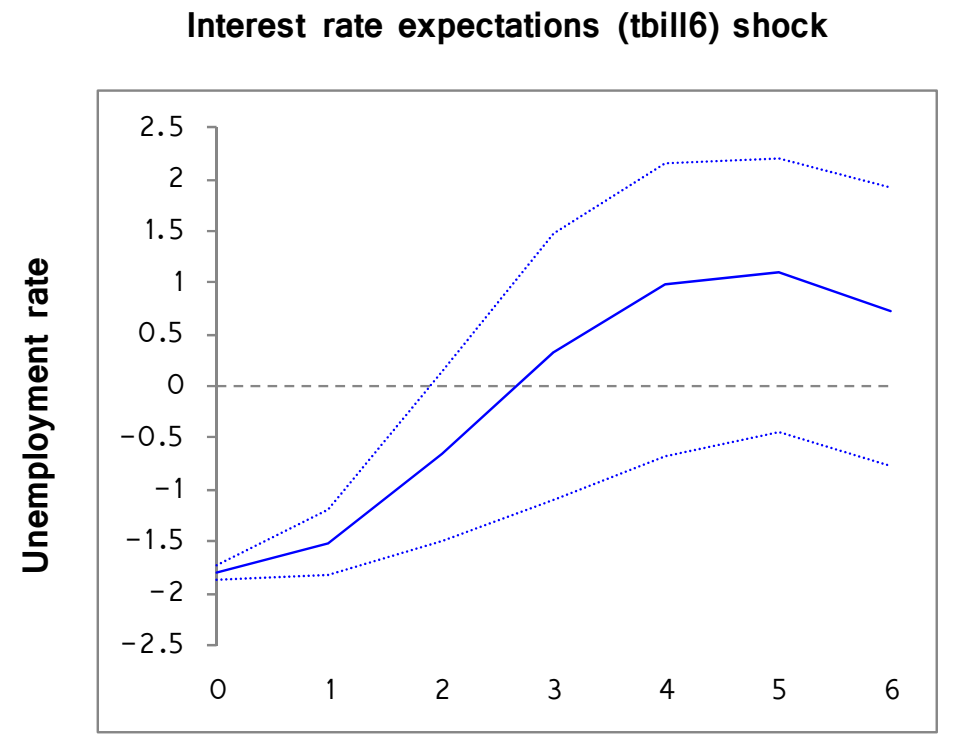

Non ZLB (1981:Q3-2008:Q1)
Interest rate expectations (tbill6) shock

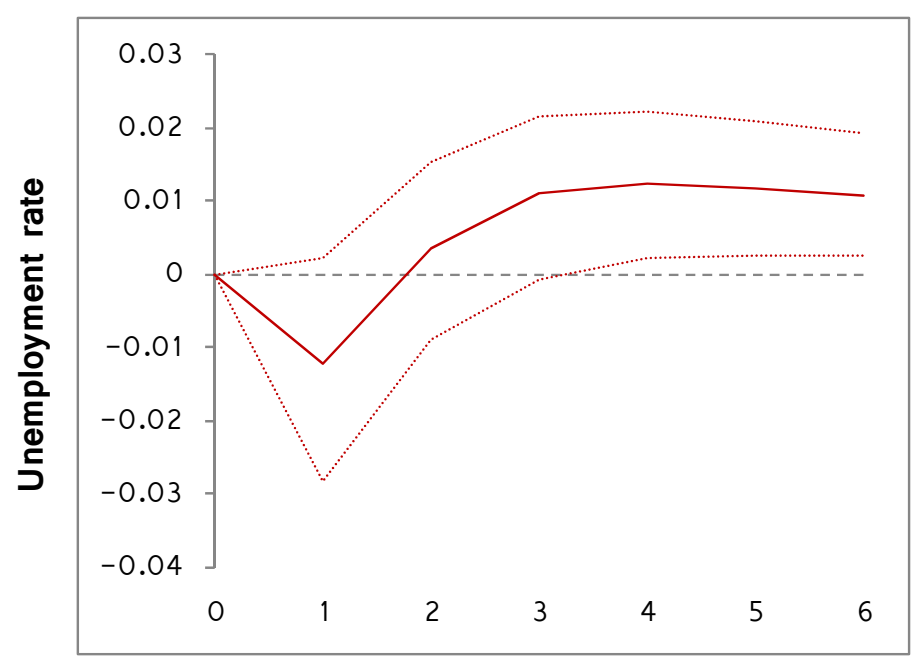

ZLB (2008:Q2-2014:Q3 )

Figure 13: Livingston Survey data 